VITAL VOICES

Issues That Impact U.S. LGBTQ Adults Age 45 and Older

December 2020

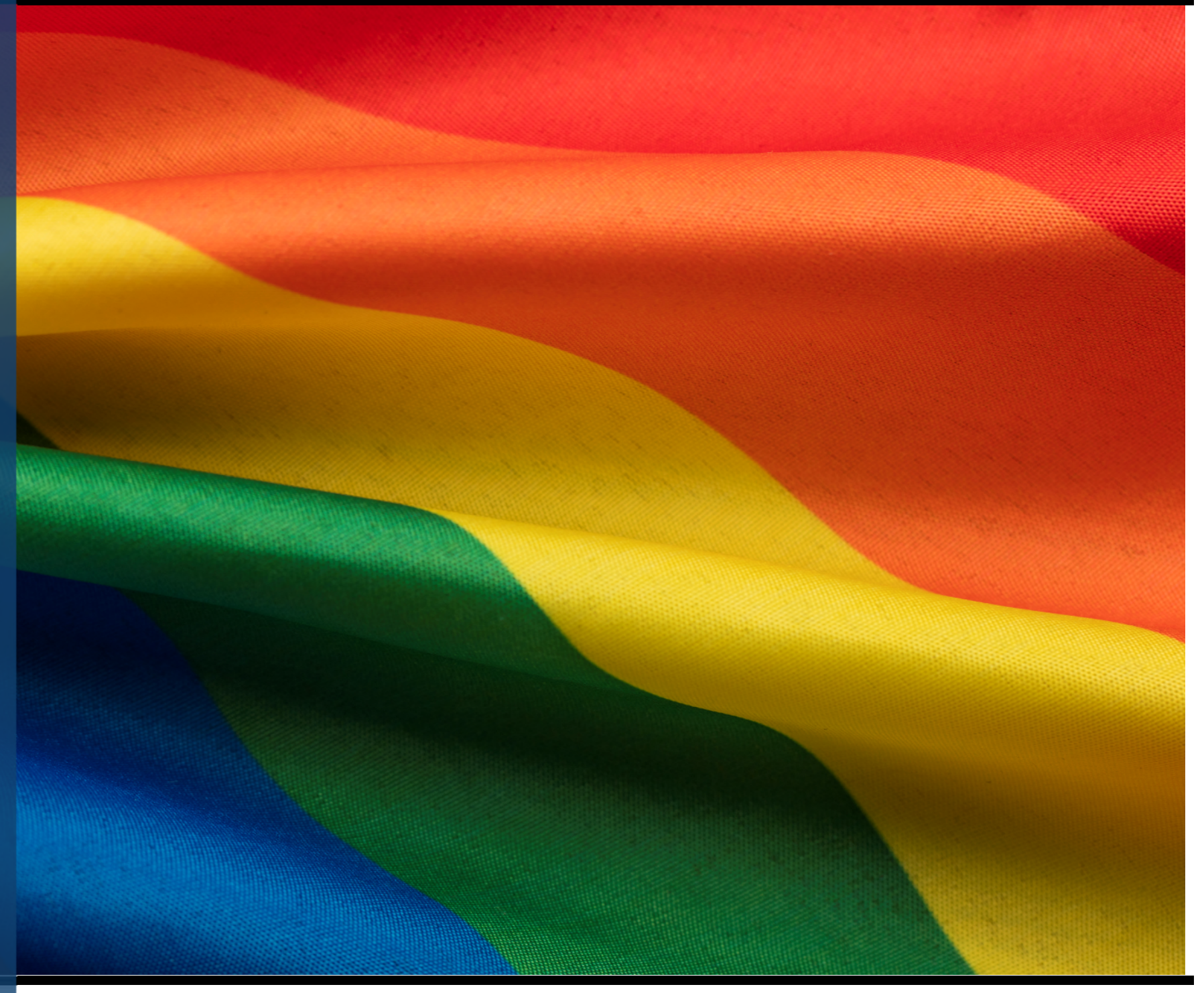




\section{TABLE OF CONTENTS}

Introduction to Vital Voices Surveys

Health Questions

4

Wealth Questions

13

Self Questions

19

Methodology

About AARP

Contact

34

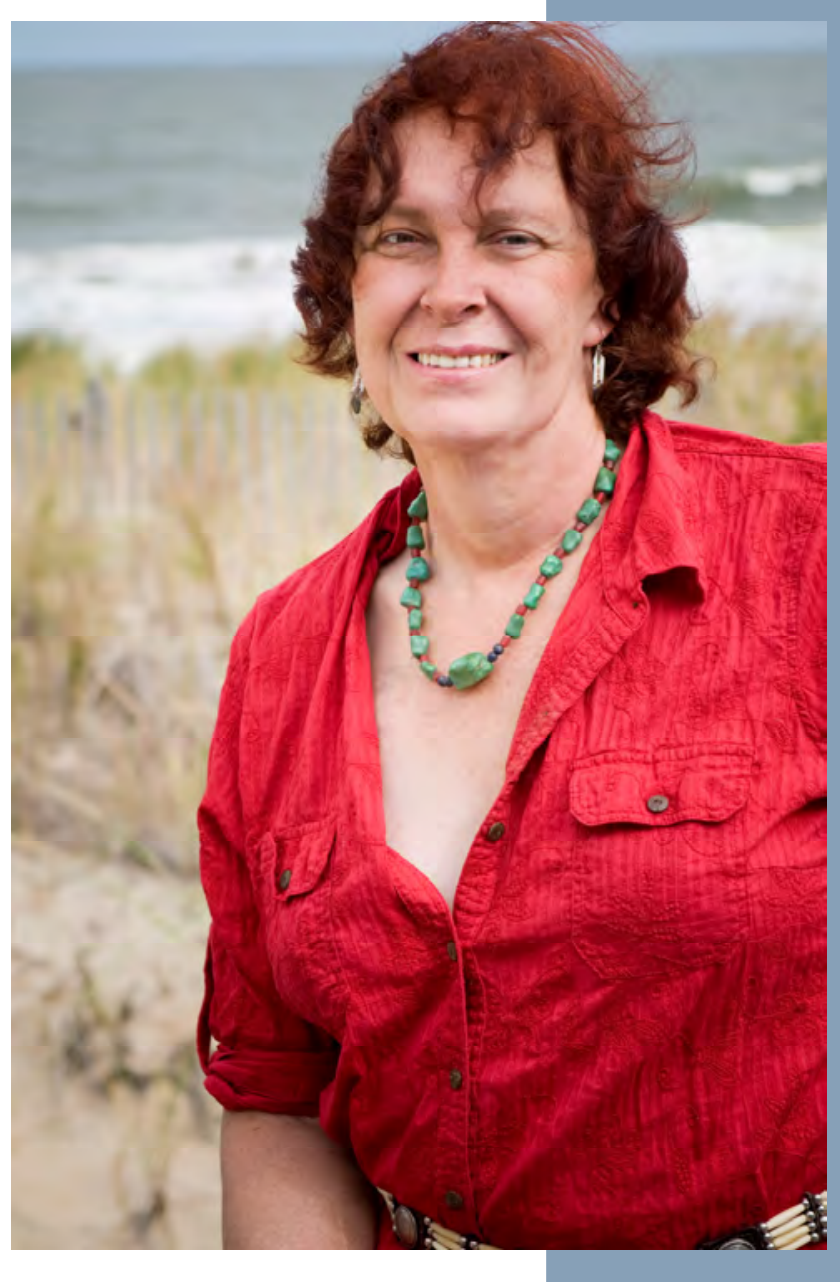




\section{INTRODUCTION}

There are currently about 117 million Americans who are 50 and older; this number will grow to 157 million by 2050 . The 50 and older population is and will continue to be an essential contributor to American society. Understanding the needs and opinions of older Americans is critical to ensuring they live longer and healthier lives.

Vital Voices is a new and exciting program of research undertaken by AARP. Through this research program, we are launching a new initiative that will deliver critical, current, and state-specific data on a rolling three-year schedule between 2019 and 2021. We are making this data available to the public to assist with the development of programs, products, and policies for older adults. This data will allow those in leadership positions to:

- Predict the need for a specific program or interest in a particular issue.

- Enhance program and product innovation and development.

- Track issues and attitudes over time to assess shifts in public opinion.

- Take action on critical advocacy issues.

Never before has AARP launched a research program of this size and with this much promise. We give it to you, hoping that it will significantly impact the work you do.

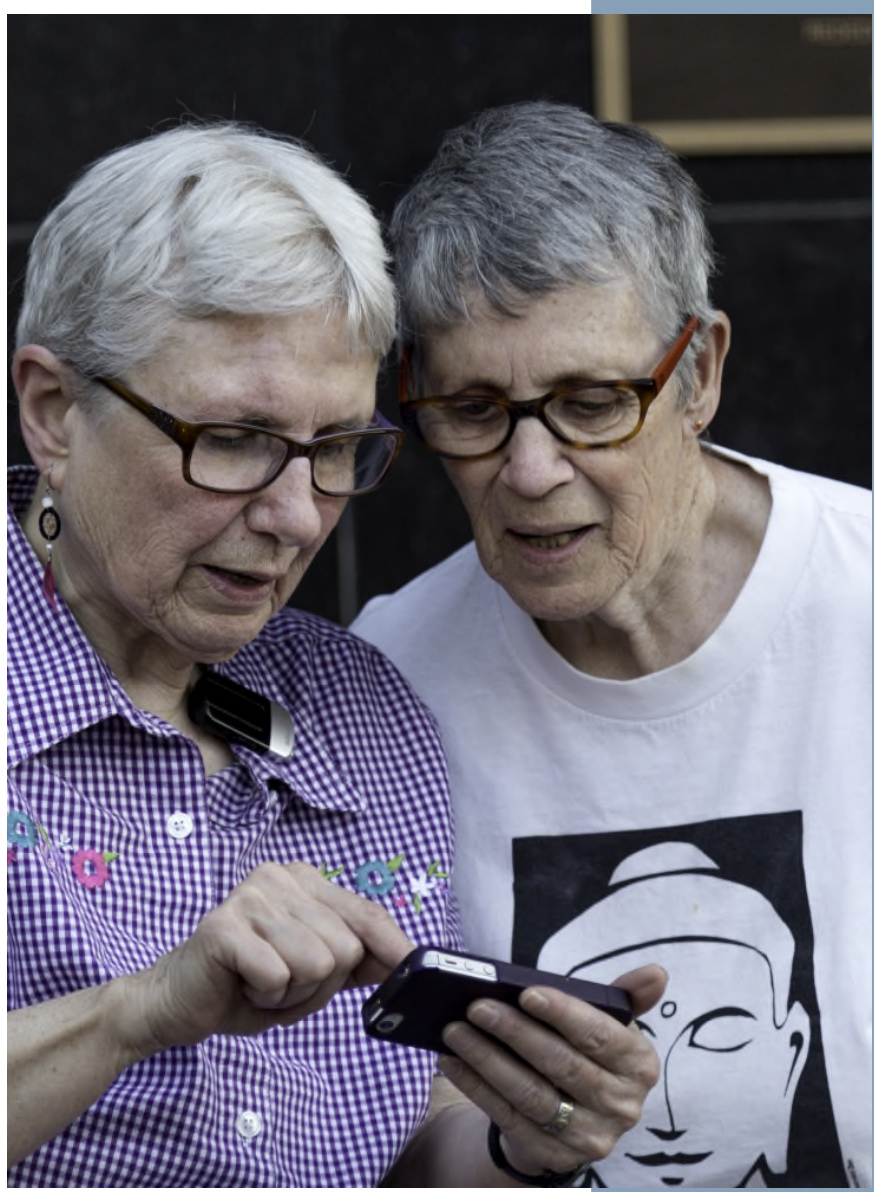




\section{National Survey}

Results

Health Questions

Issues That Impact U.S. LGBTQ Adults Age 45 and Older
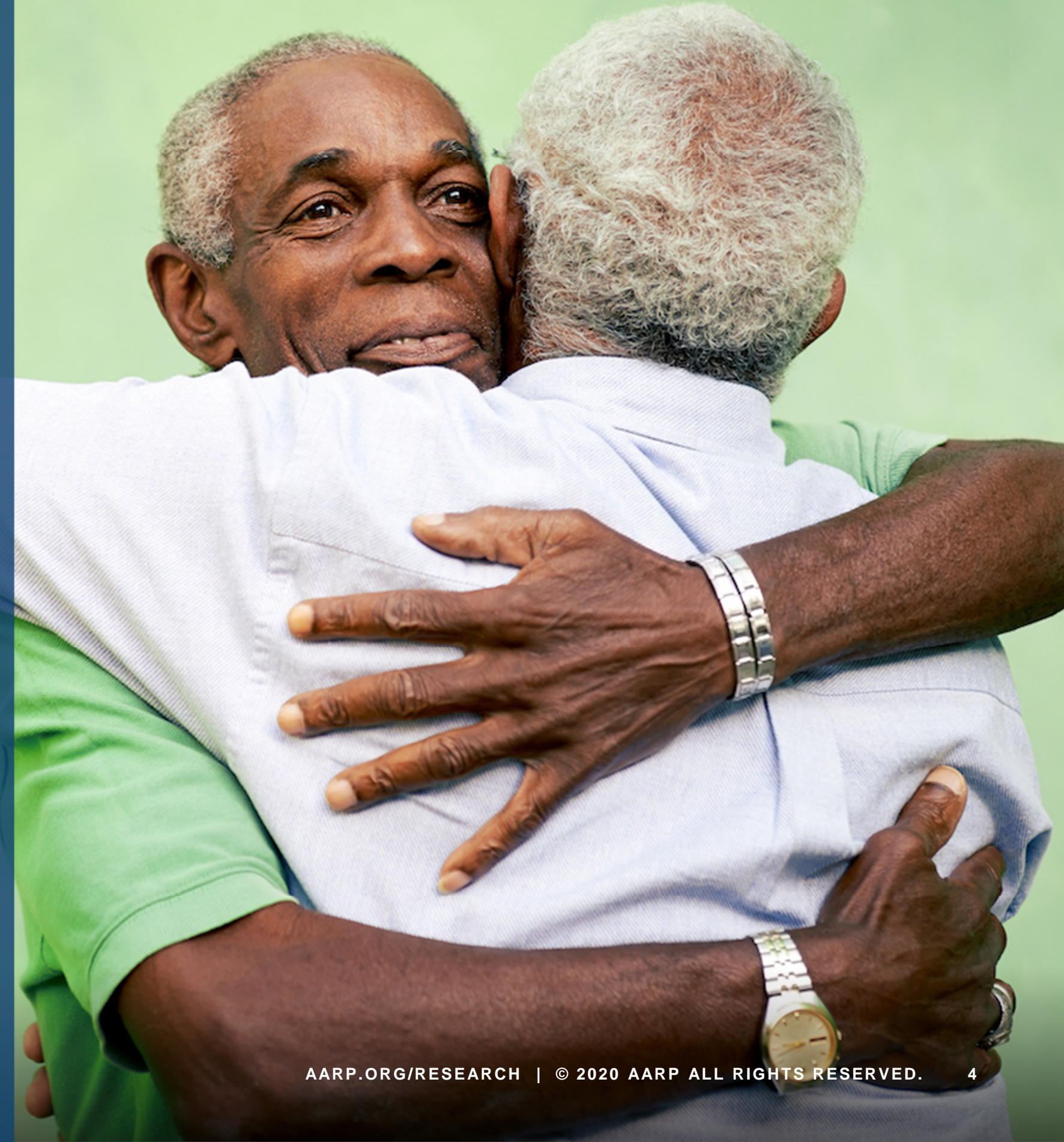


\section{ISSUES OF IMPORTANCE}

U.S. LGBTQ adults age 45+ think many healthcare issues are important, with staying mentally sharp and physically healthy toping the list. Also, having Medicare and adequate health insurance are equally top priorities.

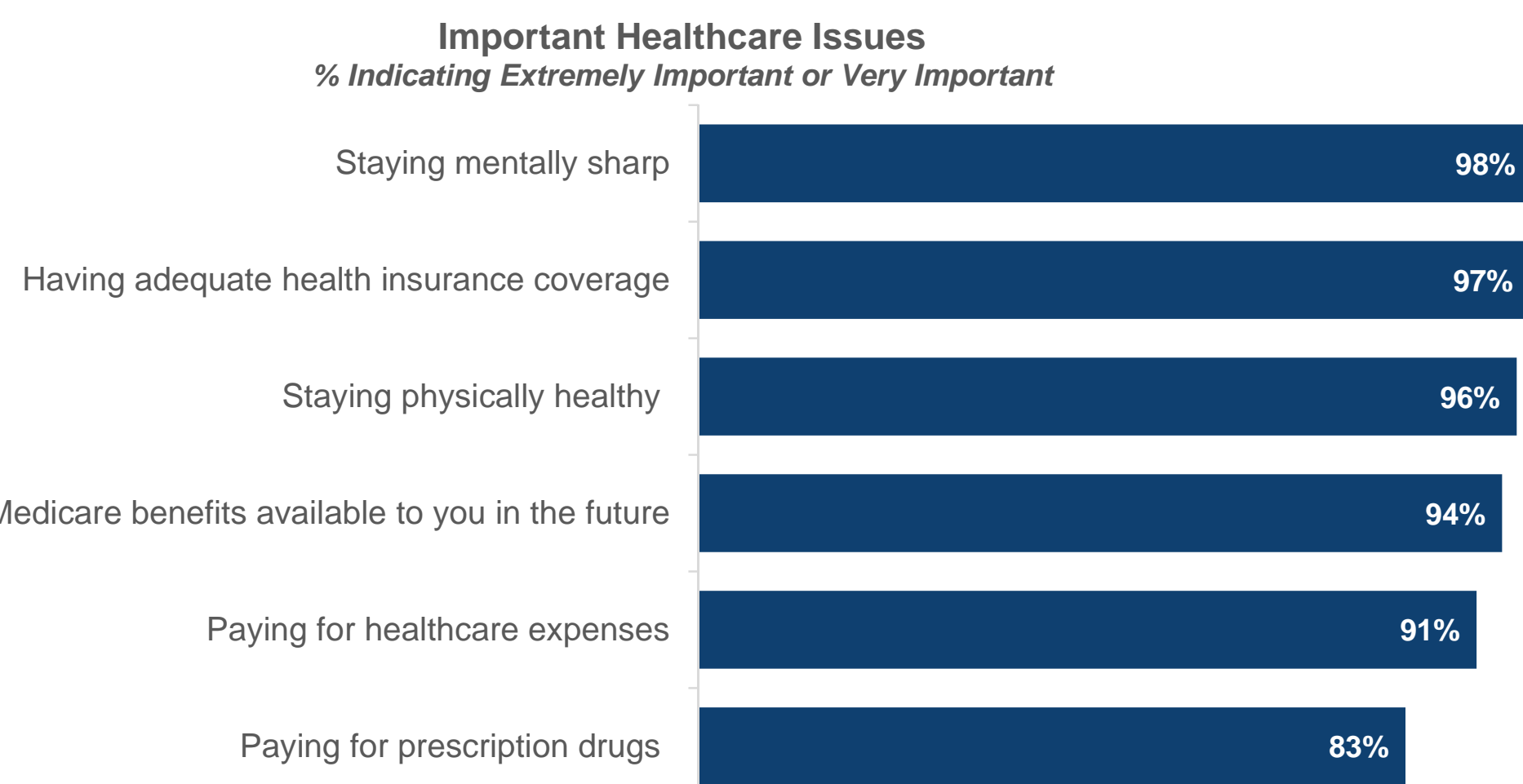




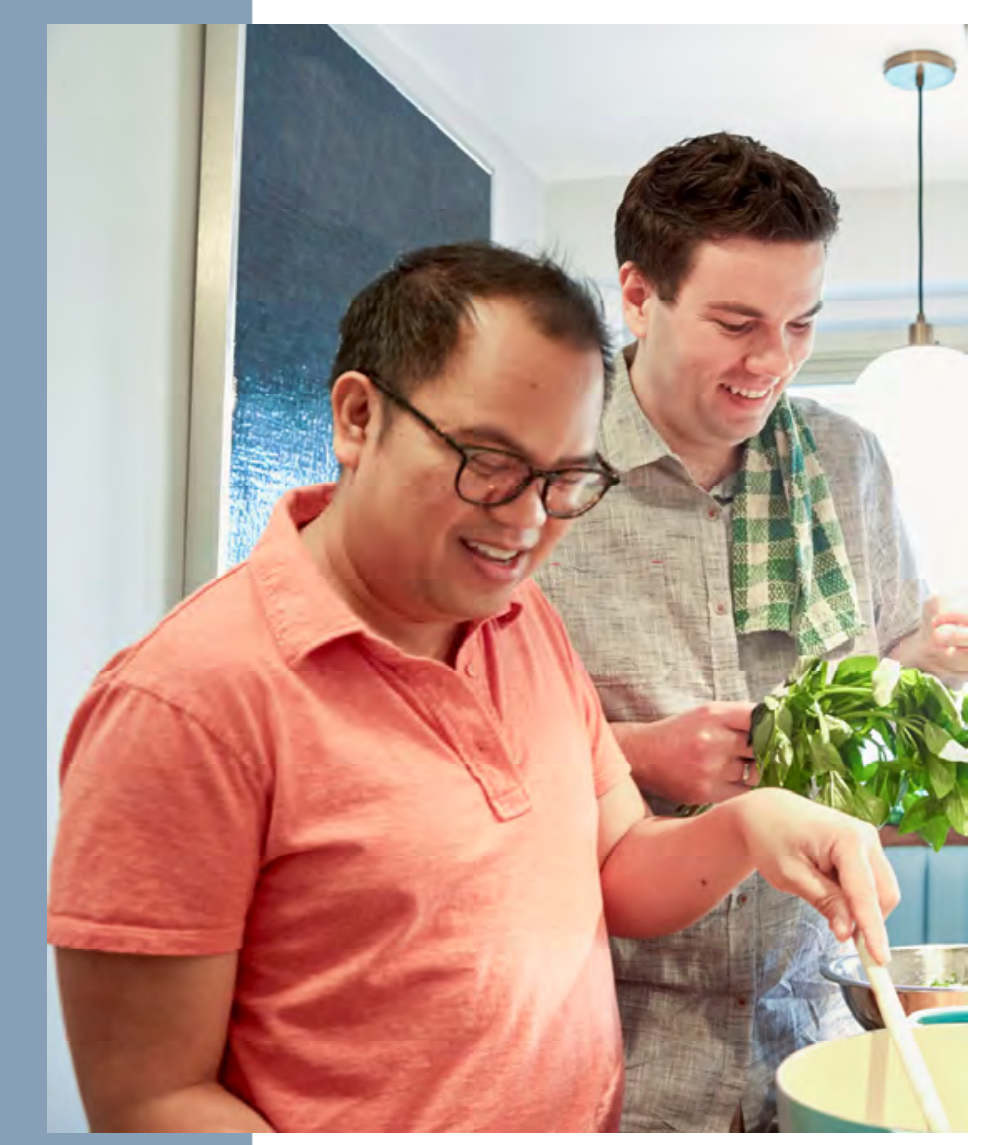

\section{CAREGIVING ISSUES}

About one-third (30\%) of U.S. LGBTQ adults age $45+$ are currently providing unpaid help to an adult relative or friend.

Are you currently providing unpaid help to a relative or friend 18 years or older to help them take care of themselves? This would include doing things for them such as grocery shopping, providing transportation, managing finances, arranging for

healthcare or other services, or preparing meals. $(n=530)$

\section{Percent Providing Unpaid Adult Care}

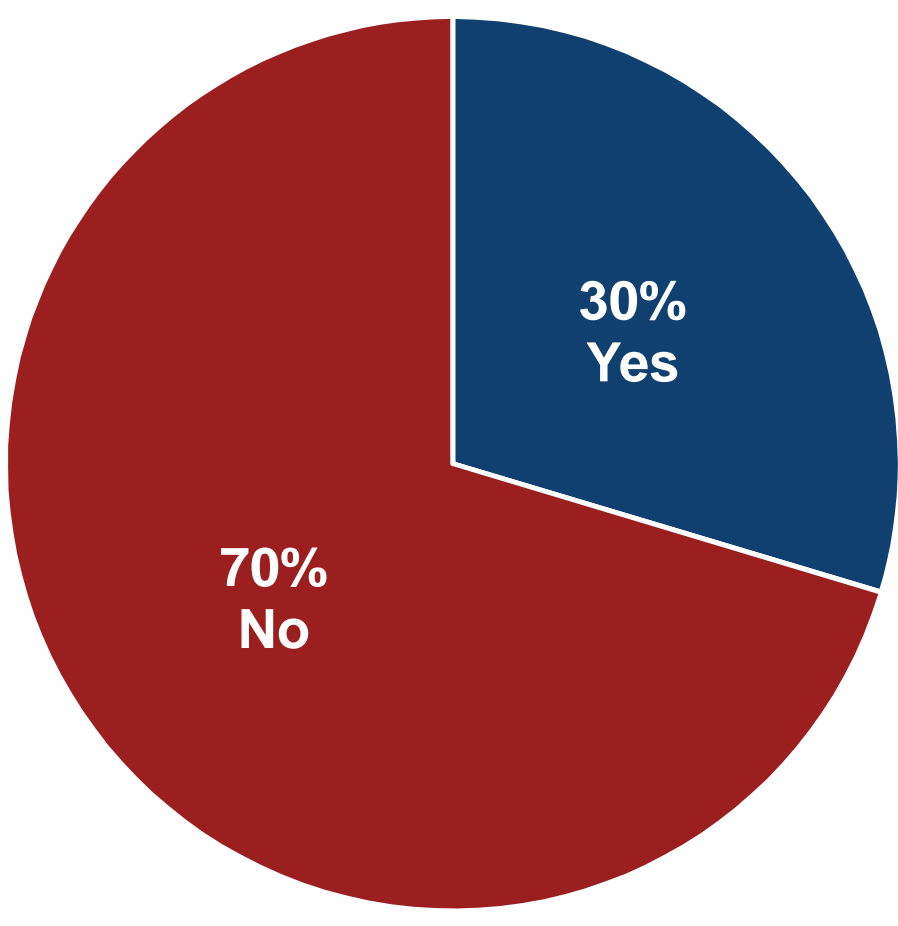




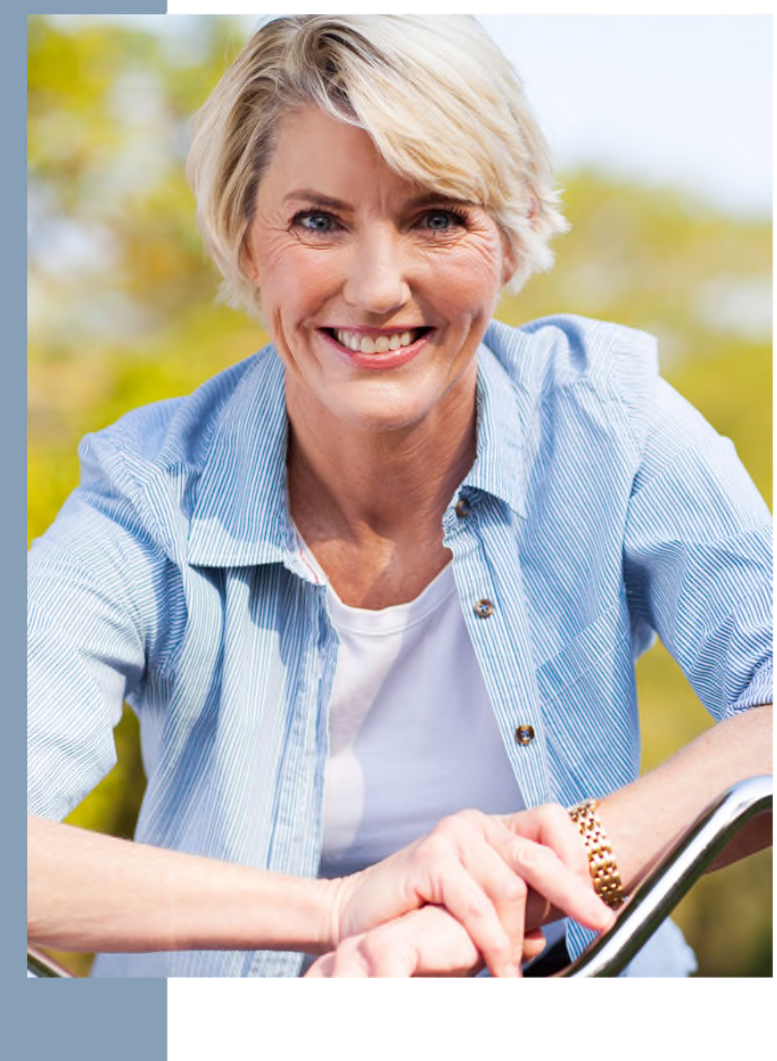

Has the coronavirus made it more difficult for you to provide care to your relative or friend? $(n=157)$

\section{CAREGIVING DURING COVID-19}

The coronavirus has made providing care more difficult for $63 \%$ of the U.S. LGBTQ caregivers in the survey.

\section{Percent Reporting that the Coronavirus Has Made Caregiving More Difficult (Among Caregivers)}

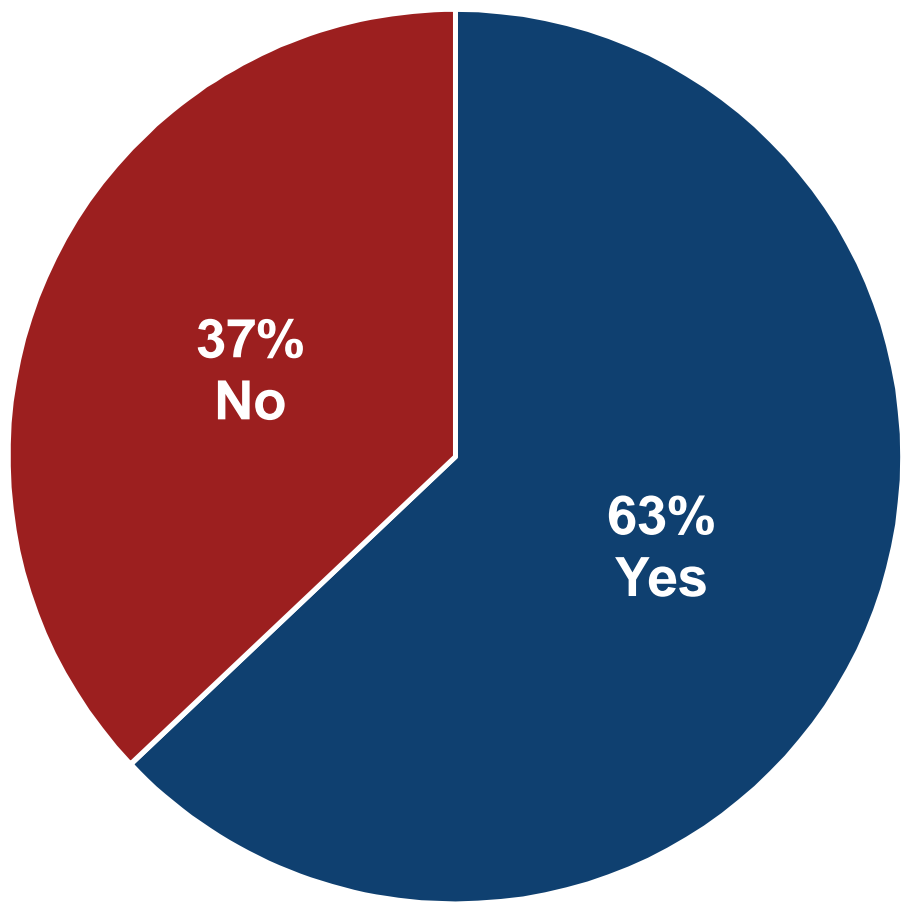




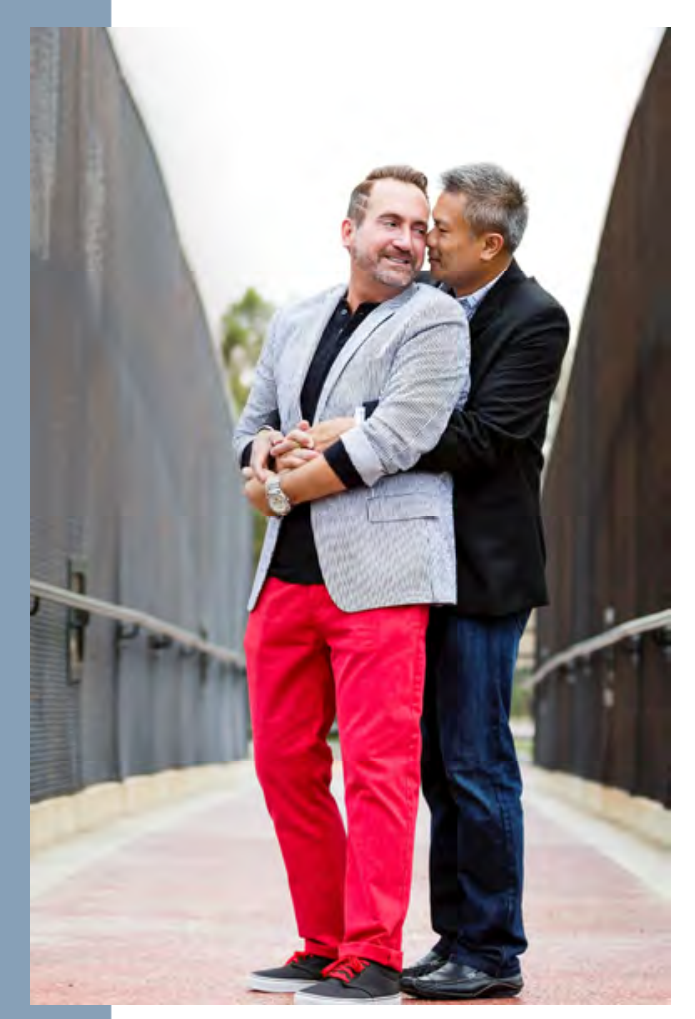

CAREGIVING ISSUES

$46 \%$ of the U.S. LGBTQ adults age $45+$ who are not currently providing unpaid help have provided this type of care in the past.

Providing Unpaid Adult Care in the Past

Have you ever provided this

type of unpaid help in the past?

$(n=373)$

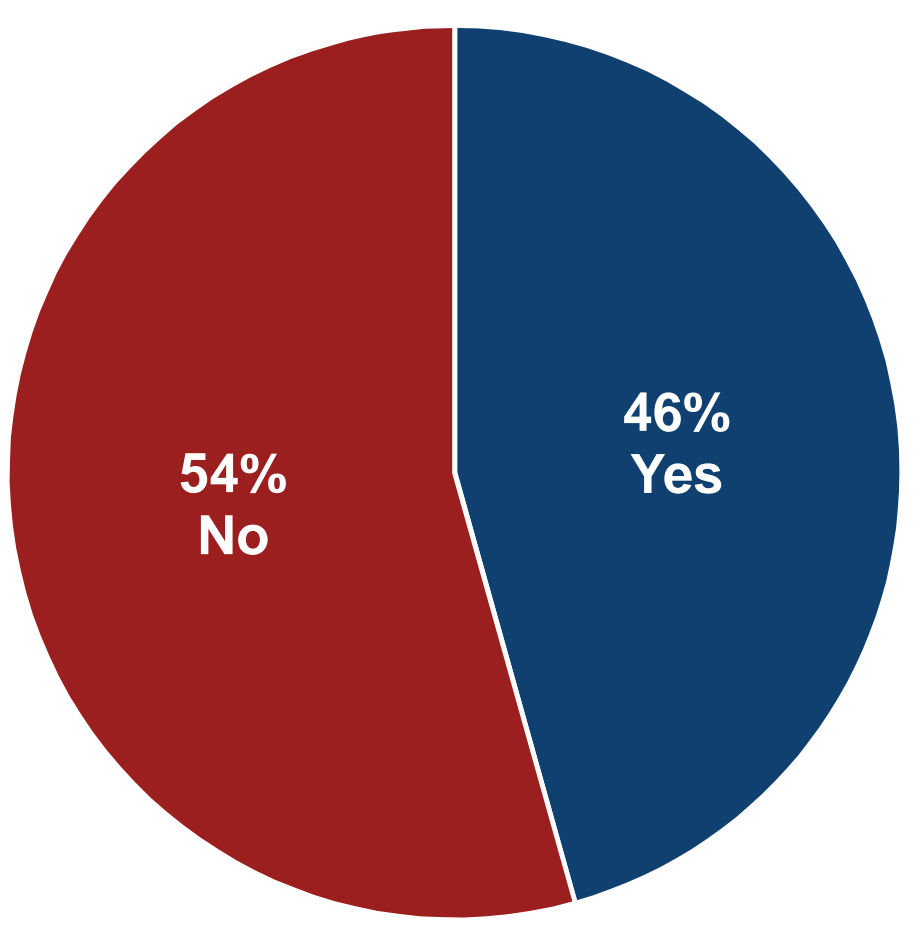




\section{IMPACTS OF COVID-19}

U.S. LGBTQ adults age $45+$ have been impacted by COVID-19 in a variety of ways, many of which are increasing their social isolation.

Ways Impacted by COVID-19

Sheltering at home to avoid contact with others

Canceled travel plans

Unable to see family members

Canceled plans to attend large gatherings

Having a difficult time worrying about the coronavirus

Working from home (if not retired)

Met with physical or mental health providers using telehealth

Got tested for coronavirus

Canceled plans to volunteer

Unable to attend religious gatherings

Filed for unemployment

Lost a job

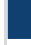
$86 \%$

$79 \%$

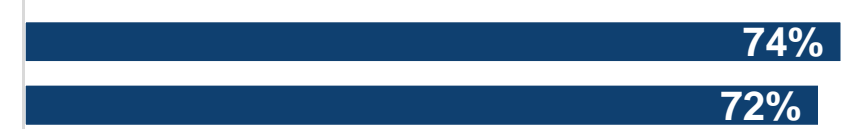

$74 \%$

$58 \%$

\section{$53 \%$}

$47 \%$

$46 \%$

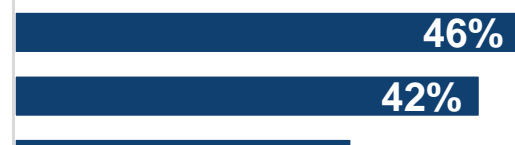

\section{$31 \%$}

$17 \%$

$16 \%$

Not having access to high-speed Internet when you need it

Officially diagnosed with coronavirus

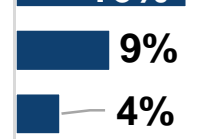




\section{IMPACTS OF COVID-19}

As of December 2020, obtaining dental services has been described as somewhat hard or very hard by $29 \%$ of U.S. LGBTQ adults age $45+$. Medical care is described as somewhat hard or very hard by $22 \%$ of the participants.

\section{Difficulty Obtaining Resources Due to COVID-19}

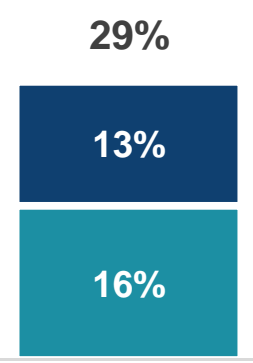

Dental services

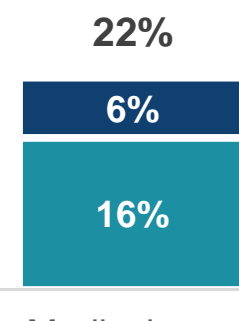

Medical care

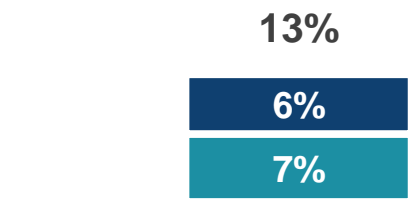

Mental health services

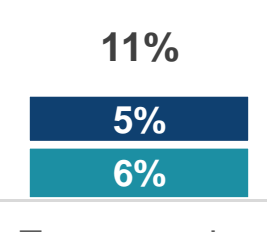

Transportation
$6 \%$

Prescription drugs

- Somewhat hard - Very hard 


\section{IMPACTS OF COVID-19}

As a result of the coronavirus pandemic, more than half (58\%) of U.S. LGBTQ adults age 45+ would be less likely to want care for themselves or a loved one in a nursing home or assisted living facility.

\section{Impact of COVID-19 on Opinion Regarding \\ Care in a Group Setting}

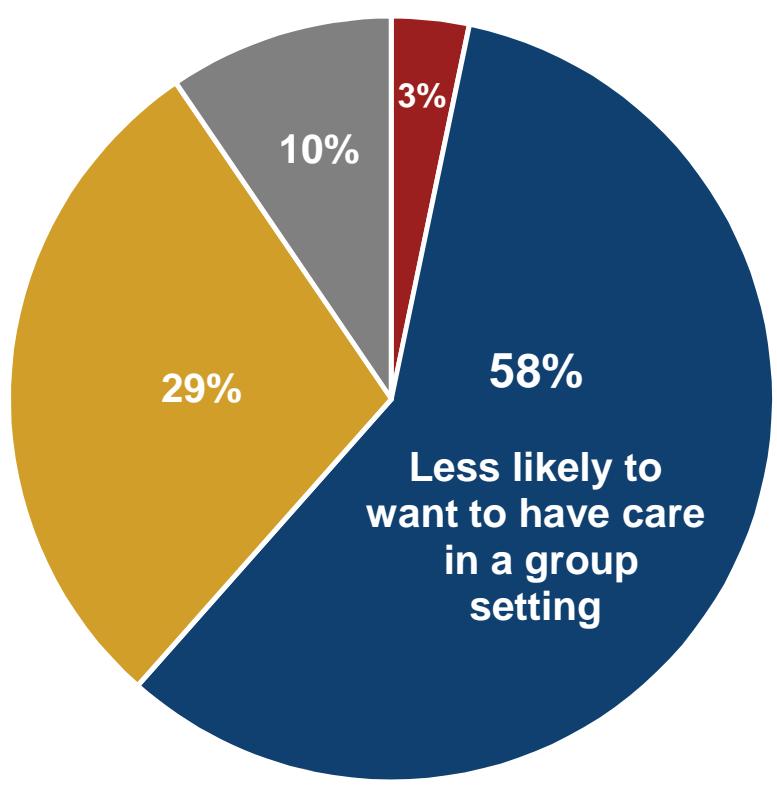

- More likely to want care in a group setting

- Not impacted opinion
- Less likely to want care in a group setting - Don't know 


\title{
IMPACTS OF COVID-19
}

$81 \%$ of LGBTQ participants are at least somewhat worried about getting COVID-19 in the next year.

\author{
Fear of COVID-19
}

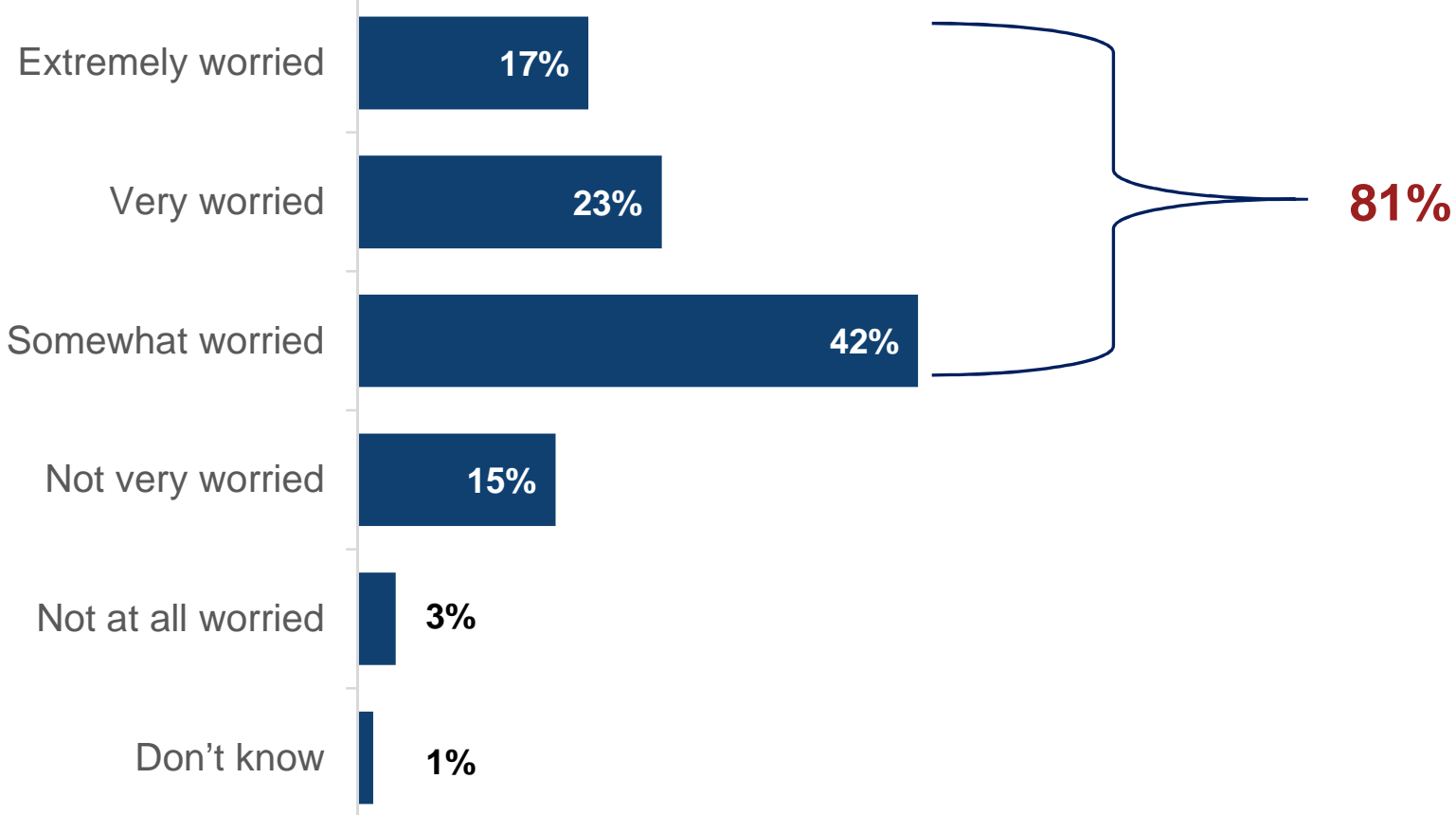




\section{National Survey Results \\ Wealth Questions}

Issues That Impact U.S. LGBTQ Adults Age 45 and Older

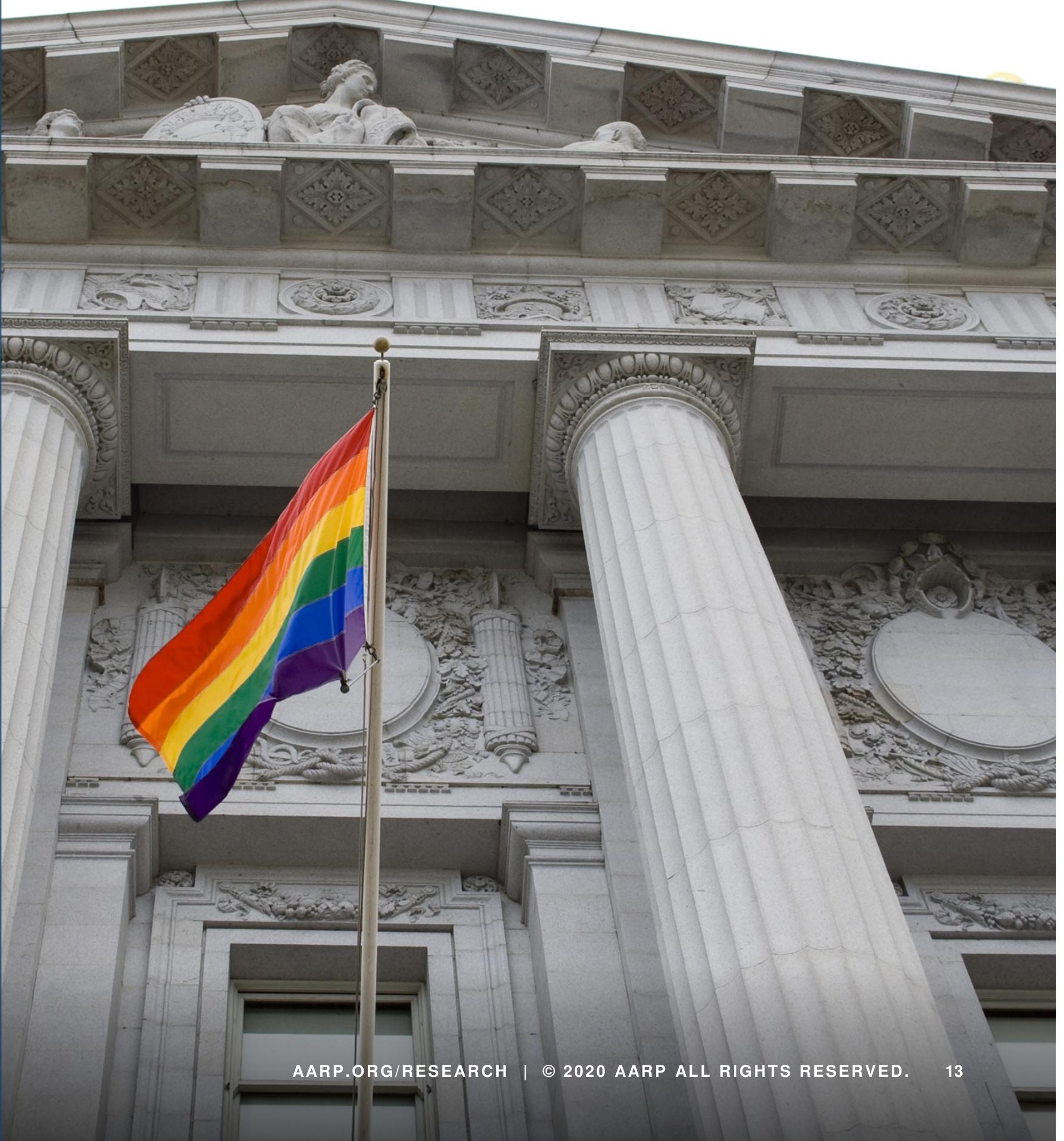




\section{ISSUES OF IMPORTANCE}

Having enough income or savings to retire, including adequate Social Security benefits, is extremely important or very important to most U.S. LGBTQ adults age 45+. Protection against fraudulent or unfair financial practices and online access/security is also critical.

Important Economic Issues

$\%$ Indicating Extremely Important or Very Important

Having enough income or savings to retire

Having adequate Social Security benefits

Protecting yourself against consumer fraud

Protecting yourself against unfair financial practices

Having online security

Protection from age discrimination

Having access to high-speed internet

Being able to stop working for pay at the age you want

Having good employment opportunities in your community

Maintaining relevant job skills and experience
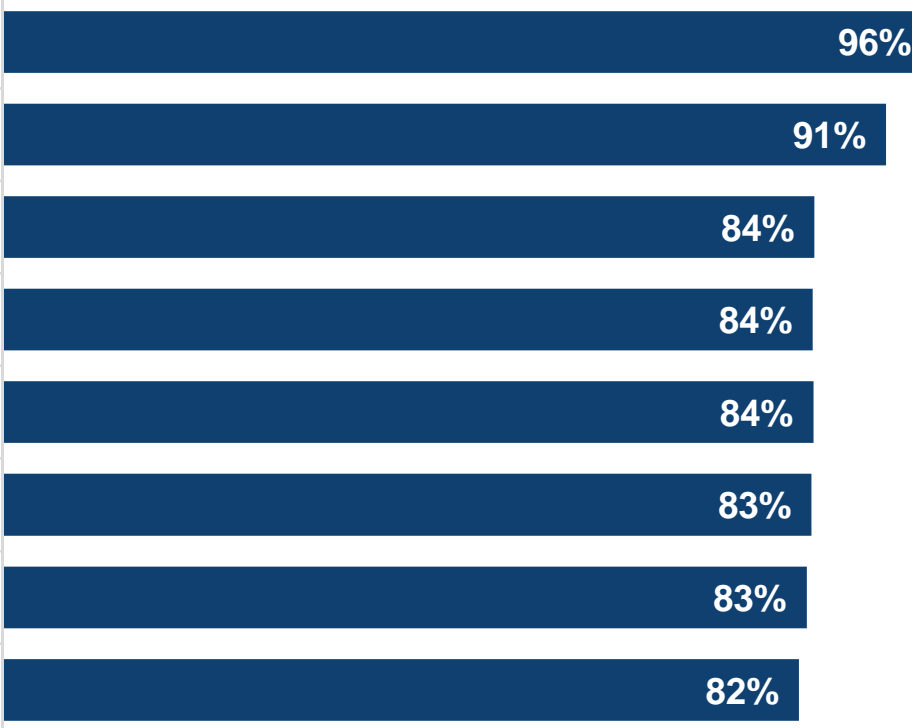

\section{$62 \%$}

$55 \%$

For the following list of issues, please indicate how important each is to you, personally.(Percent 'extremely important' or 'very important') ( $\mathrm{n}=530$ ) 


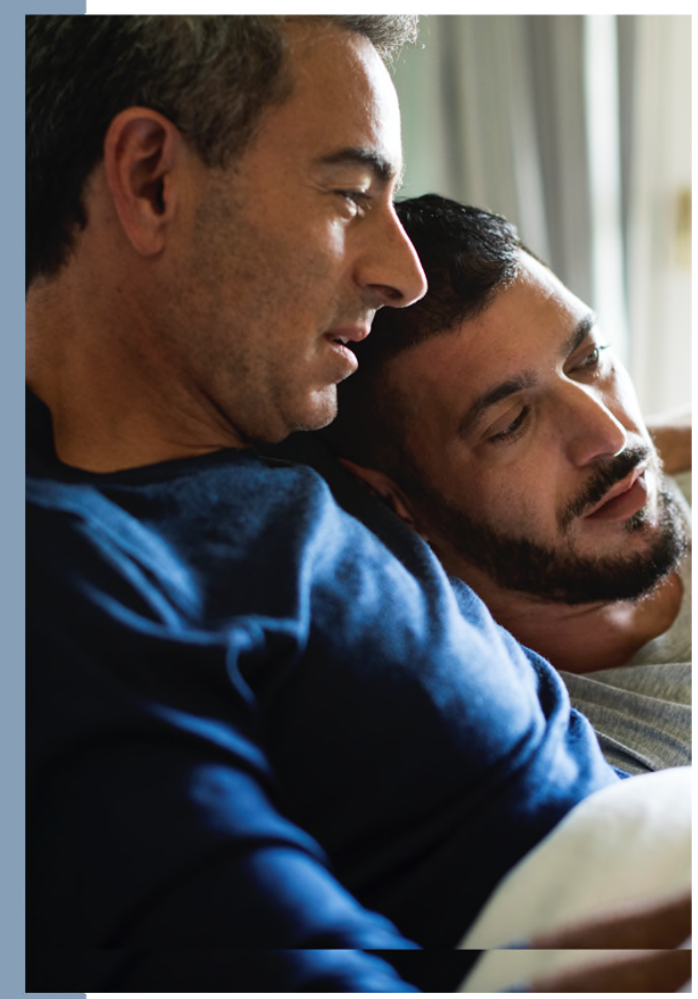

In the next 12 months, do you think your personal financial

situation will improve, get worse, or stay the same? $(n=530)$

\section{WEALTH}

Most (57\%) of U.S. LGBTQ adults age 45+ expect that their personal financial situation will stay the same in the next 12 months, $25 \%$ think it will improve, and $18 \%$ think it will get worse.
Outlook on Personal Financial Situation

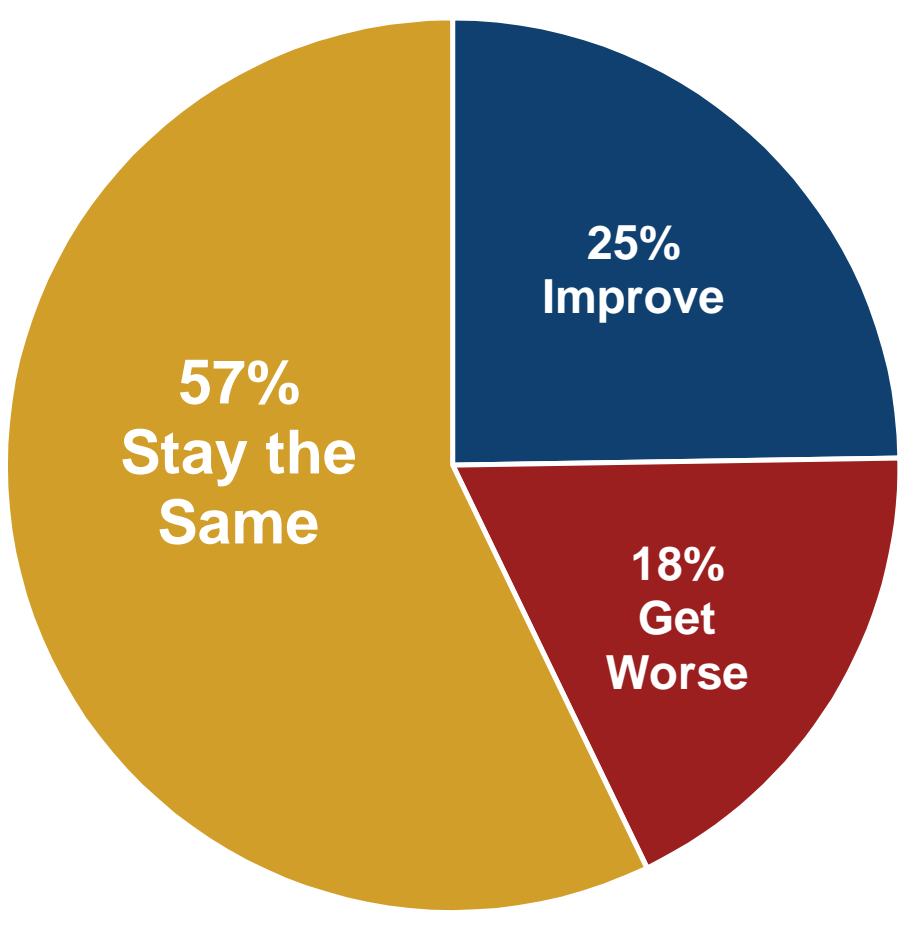




\section{RETIREMENT CONCERNS}

U.S. LGBTQ adults age 45+ have varying levels of confidence about having enough money to live comfortably throughout their retirement years.

\section{Confidence in Retirement Money Lasting}

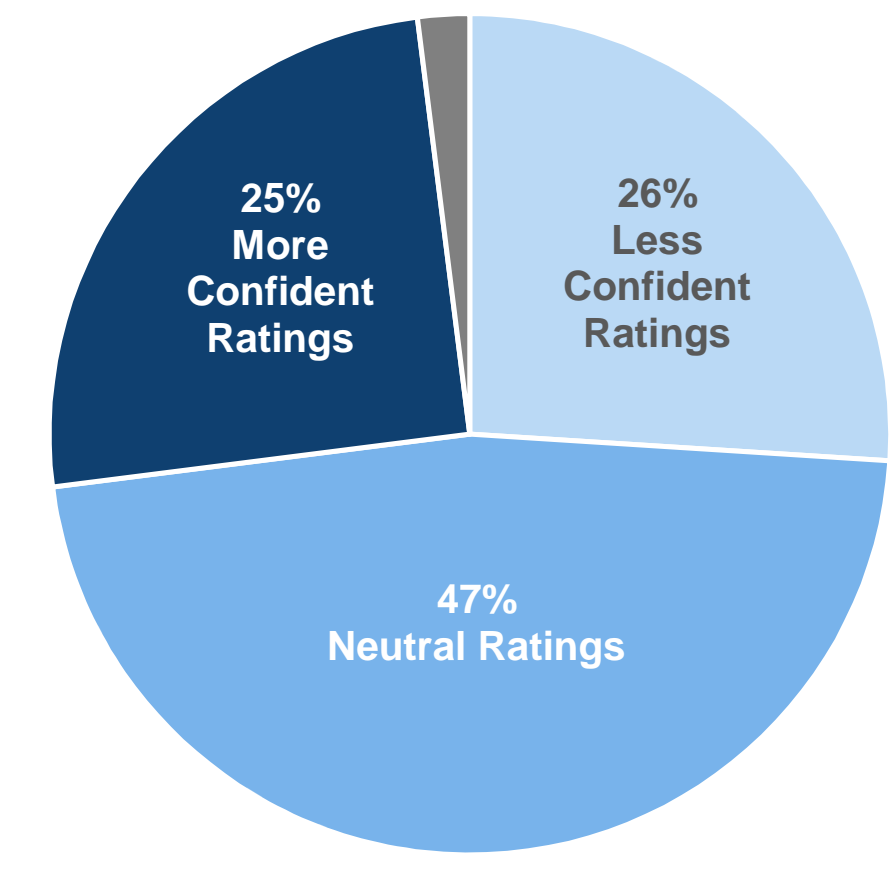

$\square$ Ratings of 1-3 $\quad$ Ratings of 4-7 $\quad$ Ratings of 8-10 $\quad$ Don't know/ refused

Overall, how confident are you that you will have enough money to live comfortably throughout your retirement years? Please use a 1 to 10 scale, where 1 means you are not confident at all and 10 means you are extremely confident. $(n=530)$ 


\section{FUTURE INCOME}

$83 \%$ of U.S. LGBTQ adults age $45+$ are currently relying on (or plan to rely on) Social Security as a source of income as they get older. Just over half $(52 \%)$ will rely on savings and $401(k)$ programs.

Sources of Income Relied On or Planning to Rely On

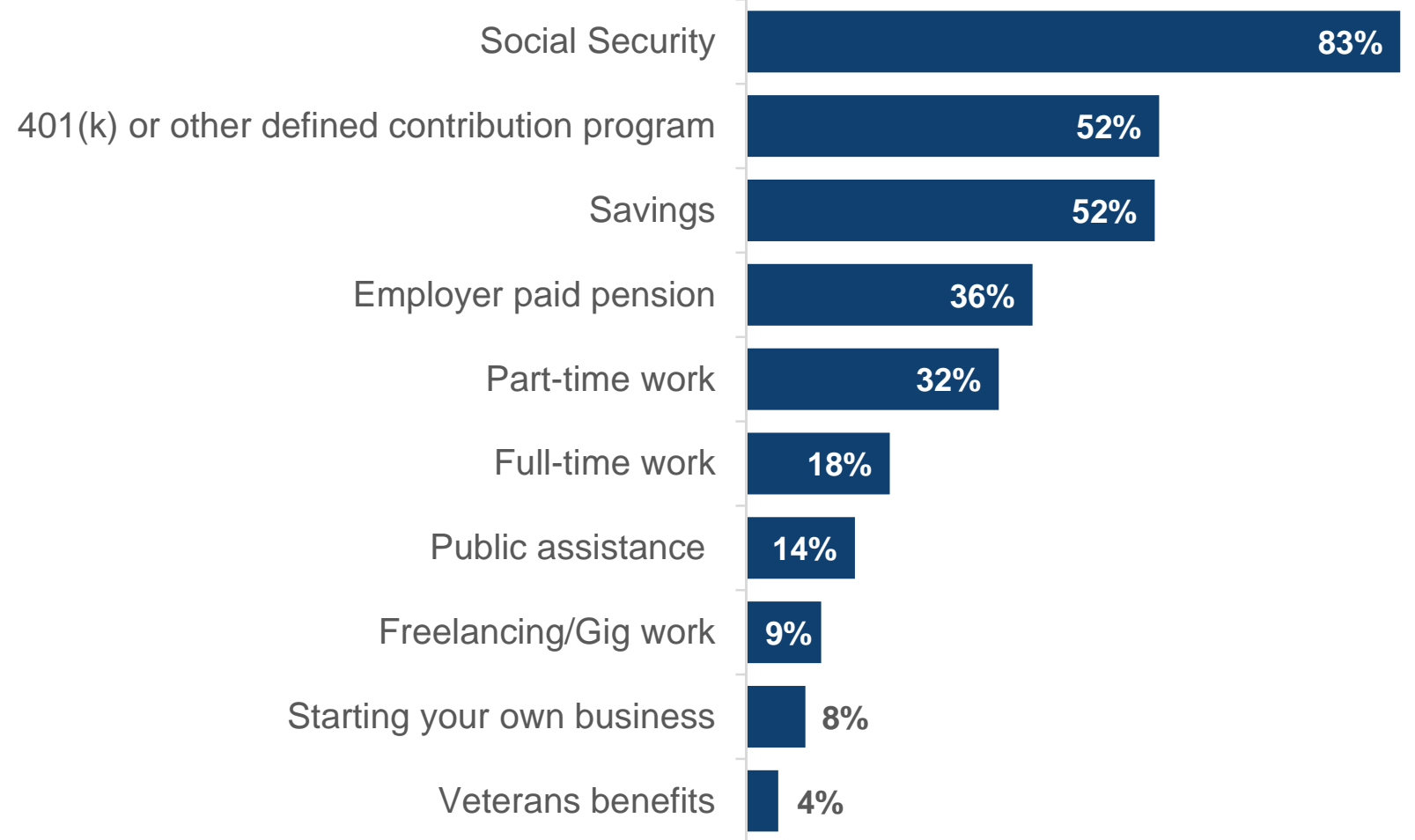

Which, if any, of the following sources of income do you currently rely on or plan to rely on as you get older? Please select all that apply. ( $\mathrm{n}=530$ ) 


\title{
WORK ISSUES
}

Most U.S. LGBTQ adults age 45+ are most interested in having flexible work arrangements $(57 \%)$ and keeping up with technology to maintain job skills $(52 \%)$.

\author{
Interest in Work-Related Opportunities \\ Indicating Extremely Interested or Very Interested
}

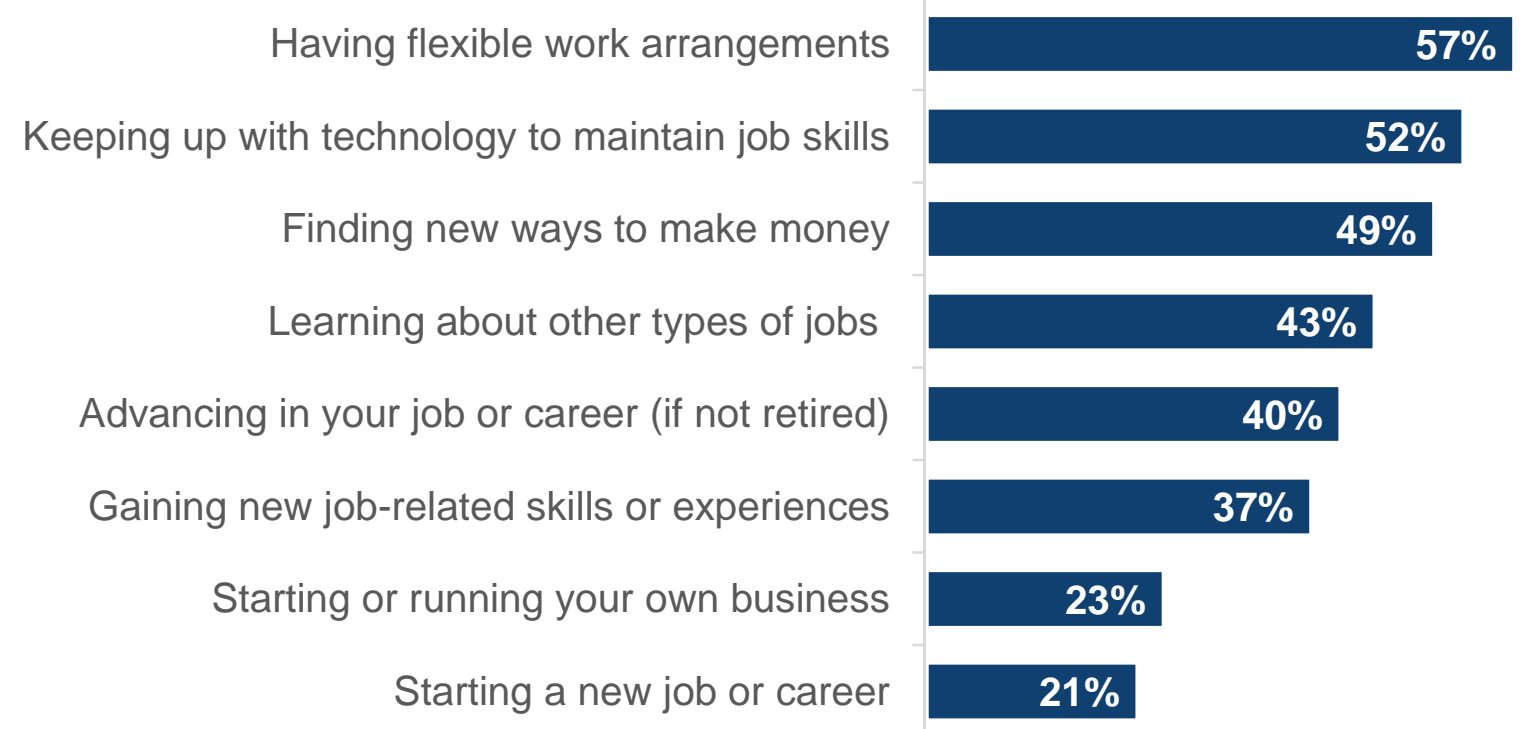

How interested are you in...? (Percent 'extremely interested' or 'very interested') $(n=530)$ 


\section{National Survey}

Results

\section{Self Questions}

Issues That Impact U.S. LGBTQ Adults Age 45 and Older

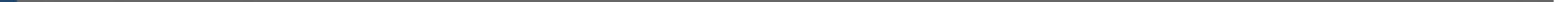




\section{ISSUES OF IMPORTANCE}

Being able to get around independently is extremely important or very important to most (92\%) U.S. LGBTQ adults age $45+$. Having alternatives to nursing home care is important to $88 \%$ of participants.

Important Independent Living Issues

$\%$ Indicating Extremely Important or Very Important

Getting to the places you need to go independently

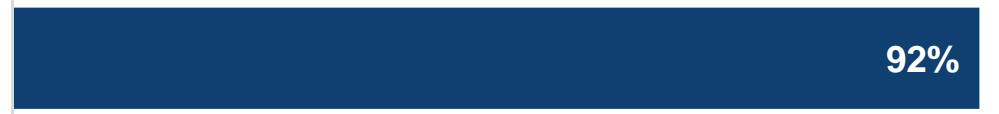

Having alternatives to nursing home care

Having high quality long-term care in your community

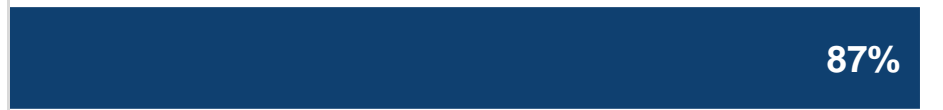

Staying in your own home as you get older

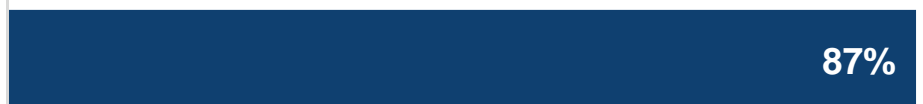

Caring for a loved one

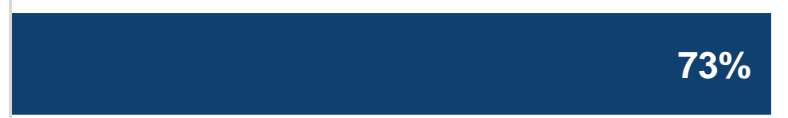

For the following list of issues, please indicate how important each is to you, personally. (Percent 'extremely important' or 'very important') $(n=530)$ 


\section{LGBTQ ASSISTED LIVING CONCERNS}

Most (56\%) of U.S. LGBTQ adults age $45+$ are concerned about facing LGBTQ-specific discrimination if they need to live in a long-term care or assisted living facility.

Fear of LGBTQ-Specific Discrimination

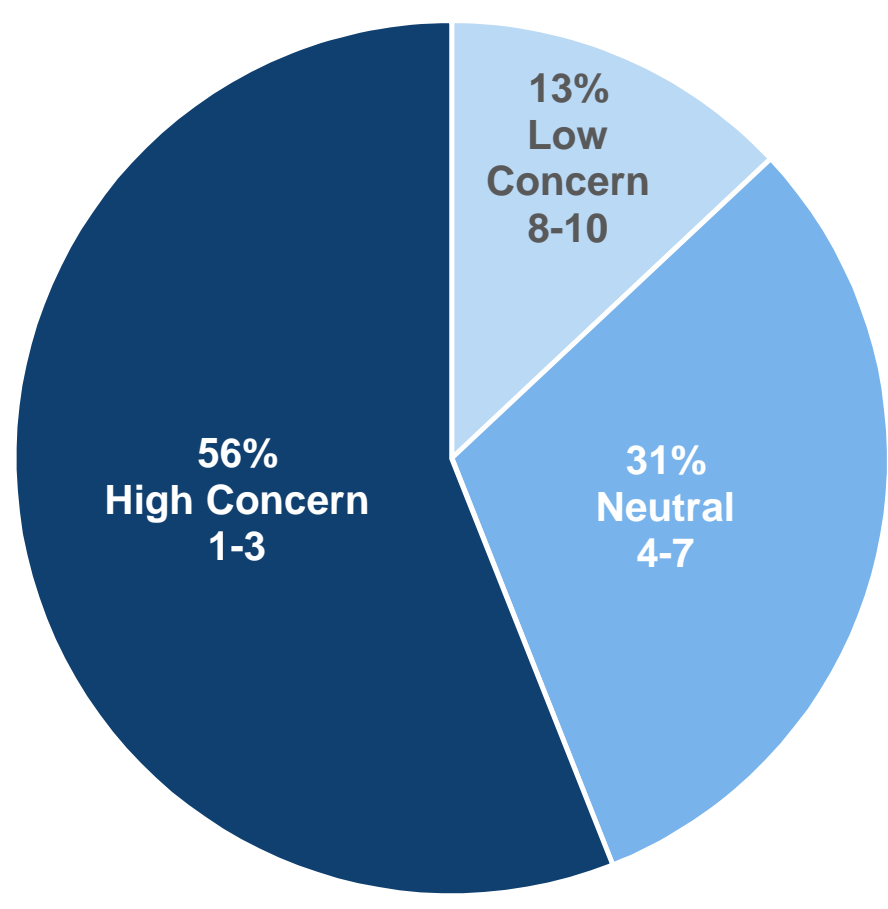

When you think of the potential of moving into an assisted living situation for older Americans, such as an assisted living apartment or a long-term care facility, how concerned are you that you might face LGBTQ-specific discrimination because of your sexual orientation or gender identity? Please use a 1 to 10 scale, where 1 means you are not concerned at all and 10 means you are extremely concerned. $(n=530)$ 


\section{COMMUNITY ISSUES}

Of the concerns listed, COVID-19 and toxic political discourse are the issues affecting U.S. LGBTQ adults age $45+$ in a negative way.

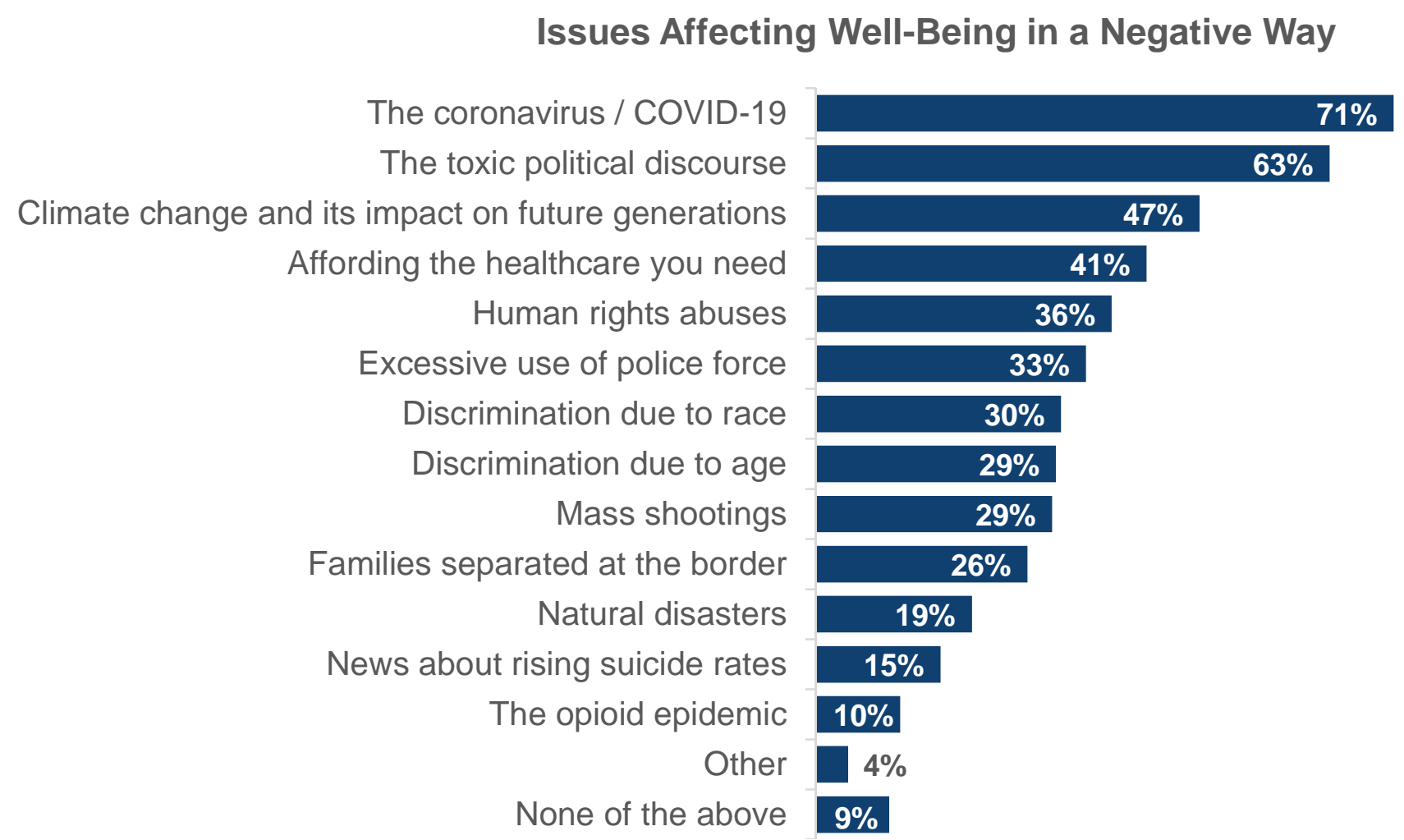




\section{COMMUNITY ISSUES}

Sexual orientation discrimination negatively affects $38 \%$ of U.S. LGBTQ adults age $45+$.

\section{Issues Affecting Well-Being in a Negative Way}

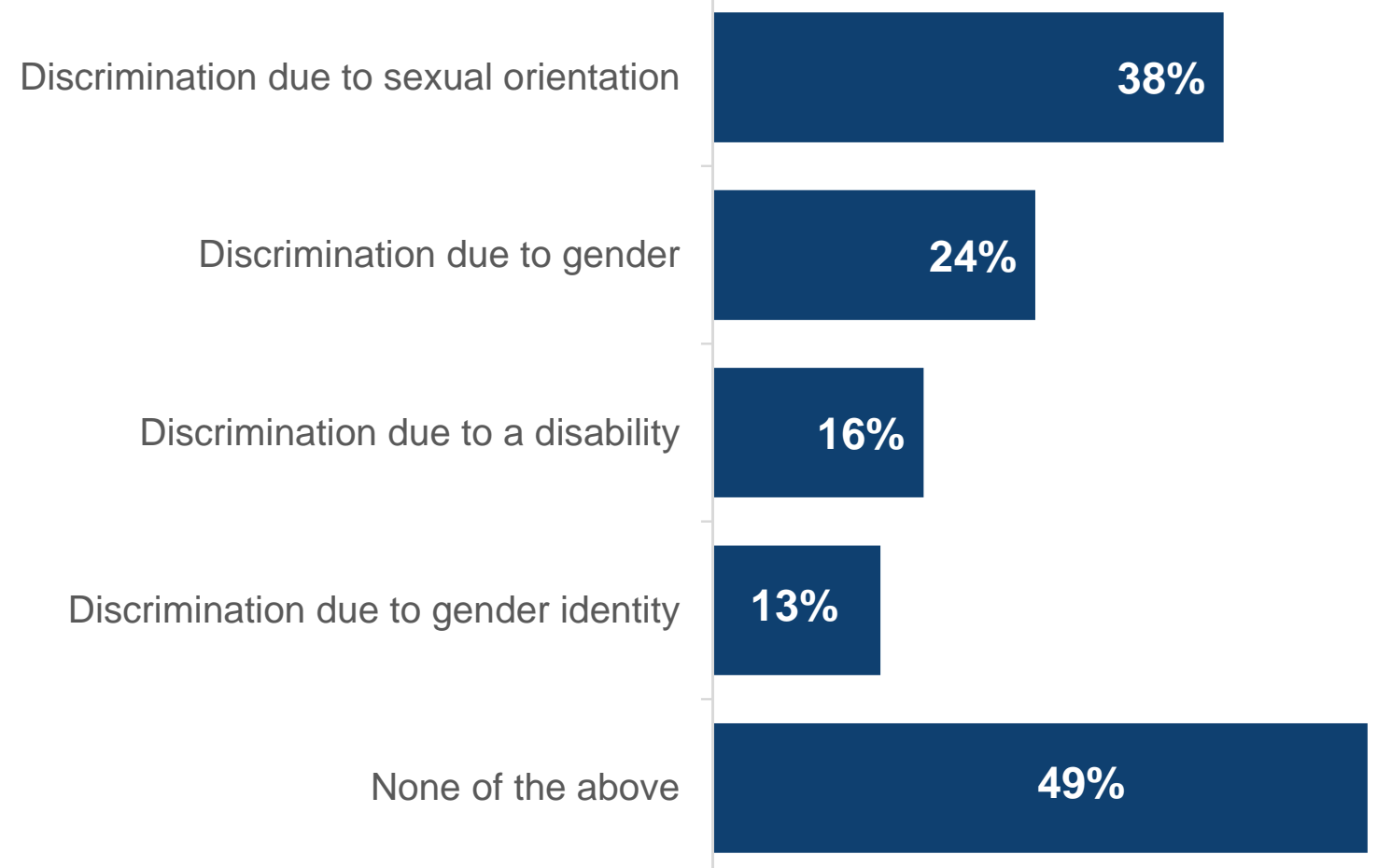

Continuing with the same question, have any of the following affected your wellbeing in a negative way? Please select all that apply. ( $\mathrm{n}=530$ ) 


\section{ISOLATION}

$61 \%$ of U.S. LGBTQ adults age $45+$ feel isolated from others at least some of the time; $56 \%$ say they lack companionship at least some of the time.

\section{Frequency of Feelings of Isolation}

Feeling isolated from others
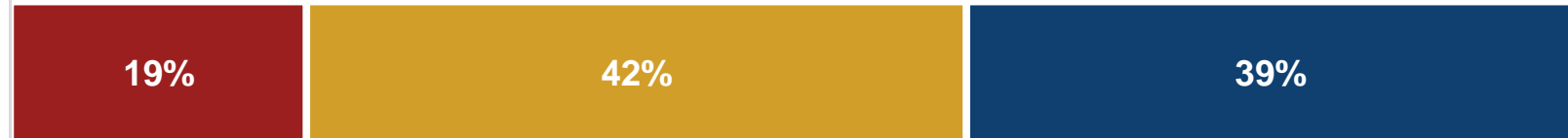

Lacking companionship
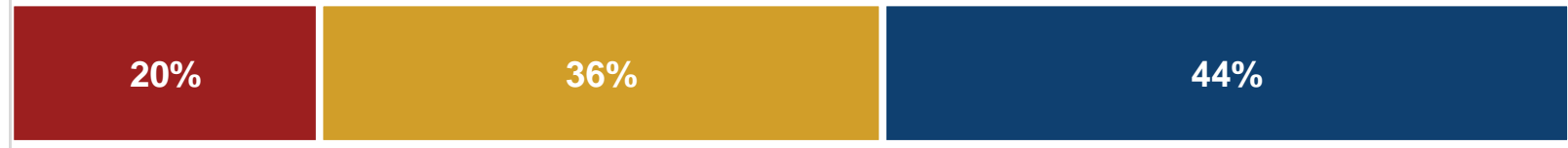

Feeling left out
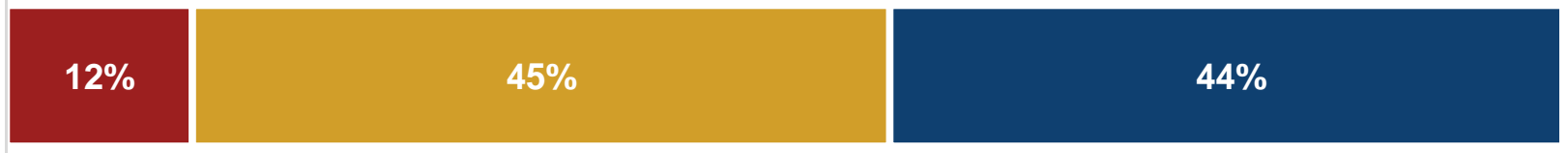

- Often

- Some of the time

- Hardly ever 


\section{LIVABLE COMMUNITIES}

More than half $(57 \%)$ of U.S. LGBTQ adults age $45+$ are extremely concerned or very concerned about being able to afford to remain in their home as they age.

\section{Concerns of U.S. LGBTQ Adults Age 45+}

Percent Indicating Extremely Concerned or Very Concerned

Being able to afford to remain in your home as you age

Being about to get around your community

Being connected with others in your community
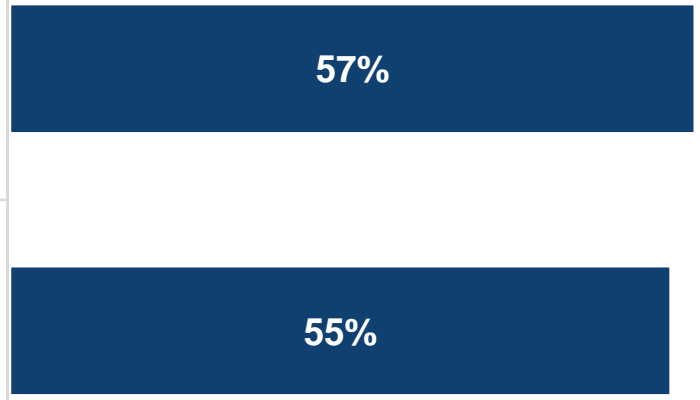

$43 \%$ 


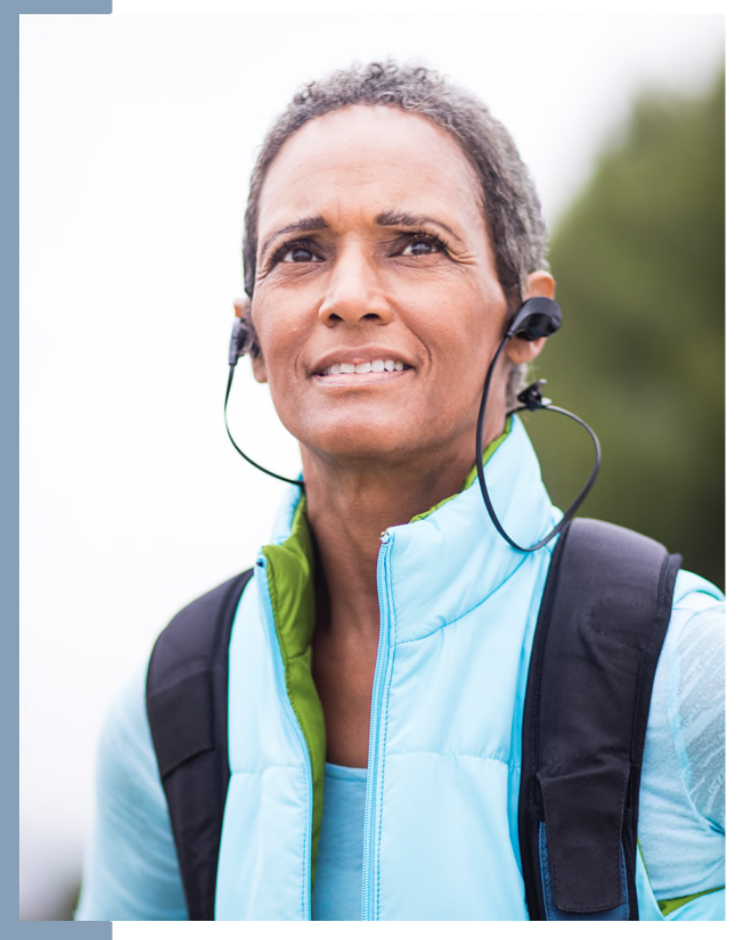

\section{RACISM}

$82 \%$ of U.S. LGBTQ adults age $45+$ believe that racism is a big problem in our society today.

\section{Racism as a Problem in Our Society Today}

How big a problem would you say racism is in our society today? $(n=530)$

'Do not know' was a response option and received less than $1 \%$

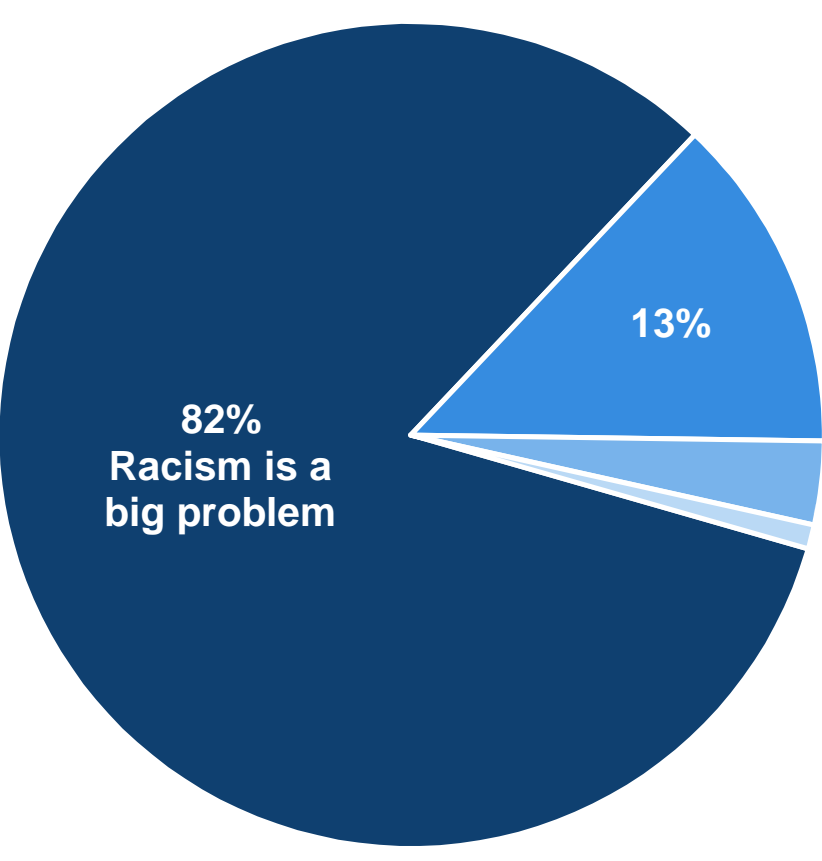

- A big problem $\quad$ Somewhat of a problem $\quad$ A small problem $\backsim$ Not a problem 


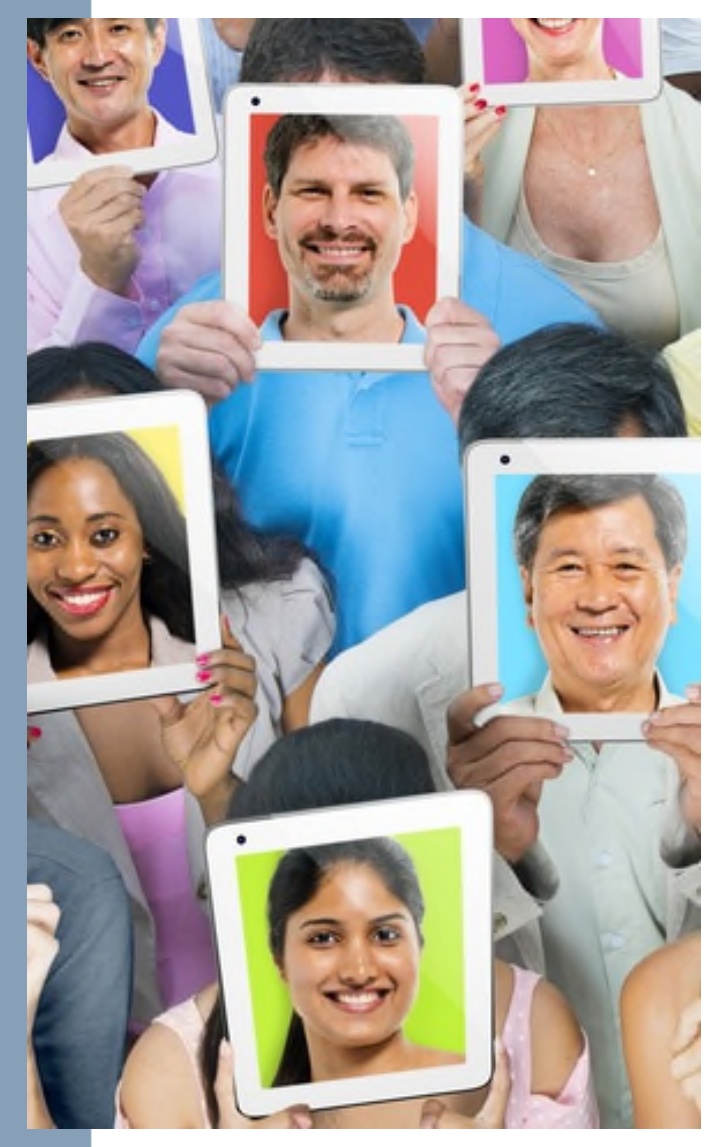

How often do you have contact with family, friends, or neighbors who do not live with you? $(n=530)$

\section{ISOLATION}

$43 \%$ of U.S. LGBTQ adults age $45+$ reported that they have contact with family, friends, or neighbors once a week or less (other than the people they live with).

Frequency of Contact with Family, Friends, or Neighbors

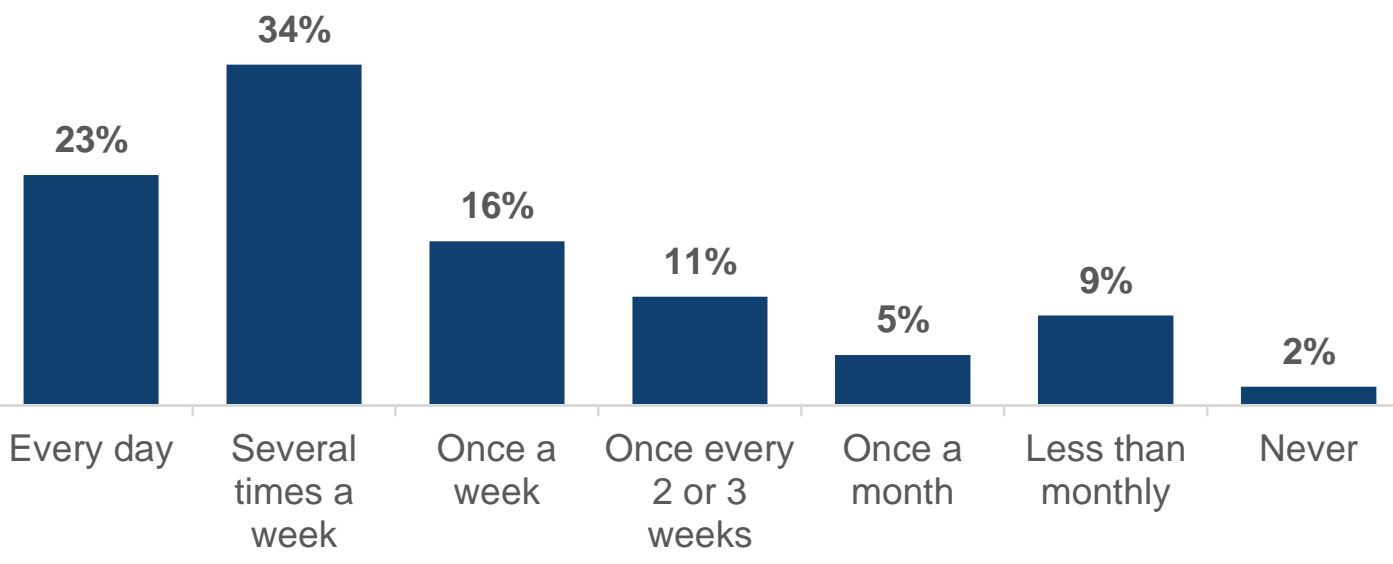




\section{ACCESS TO HIGH SPEED INTERNET}

The vast majority of U.S. LGBTQ adults age $45+$ reported that they have access to high-speed Internet services.

Other than a data plan on your cell phone, do you have high-speed Internet service at home such as cable Internet, DSL, FIOS, or satellite Internet service?

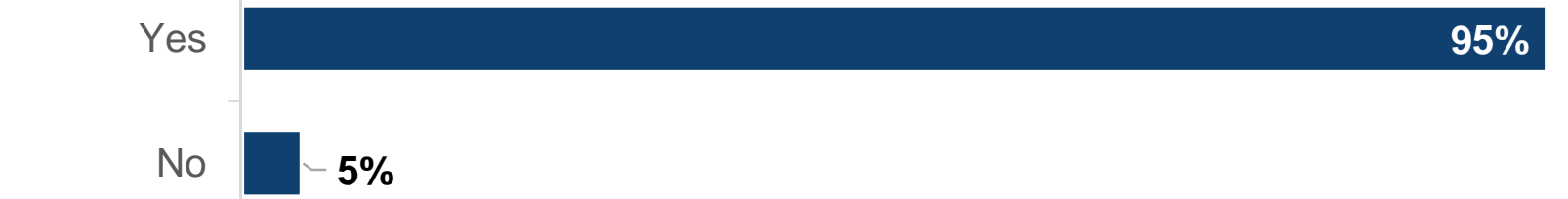

Don't know $\mid-1 \%$

Over the past few months, would you say you have had access to internet services that were [ITEM]? Percent Indicating Most of the Time

Available when needed 


\section{LIVING IN SUPPORTIVE COMMUNITIES}

Only $67 \%$ of U.S. LGBTQ adults age $45+$ indicate that they live in communities that are at least somewhat supportive of the LGBTQ community.

Living in LGBTQ Supportive Communities

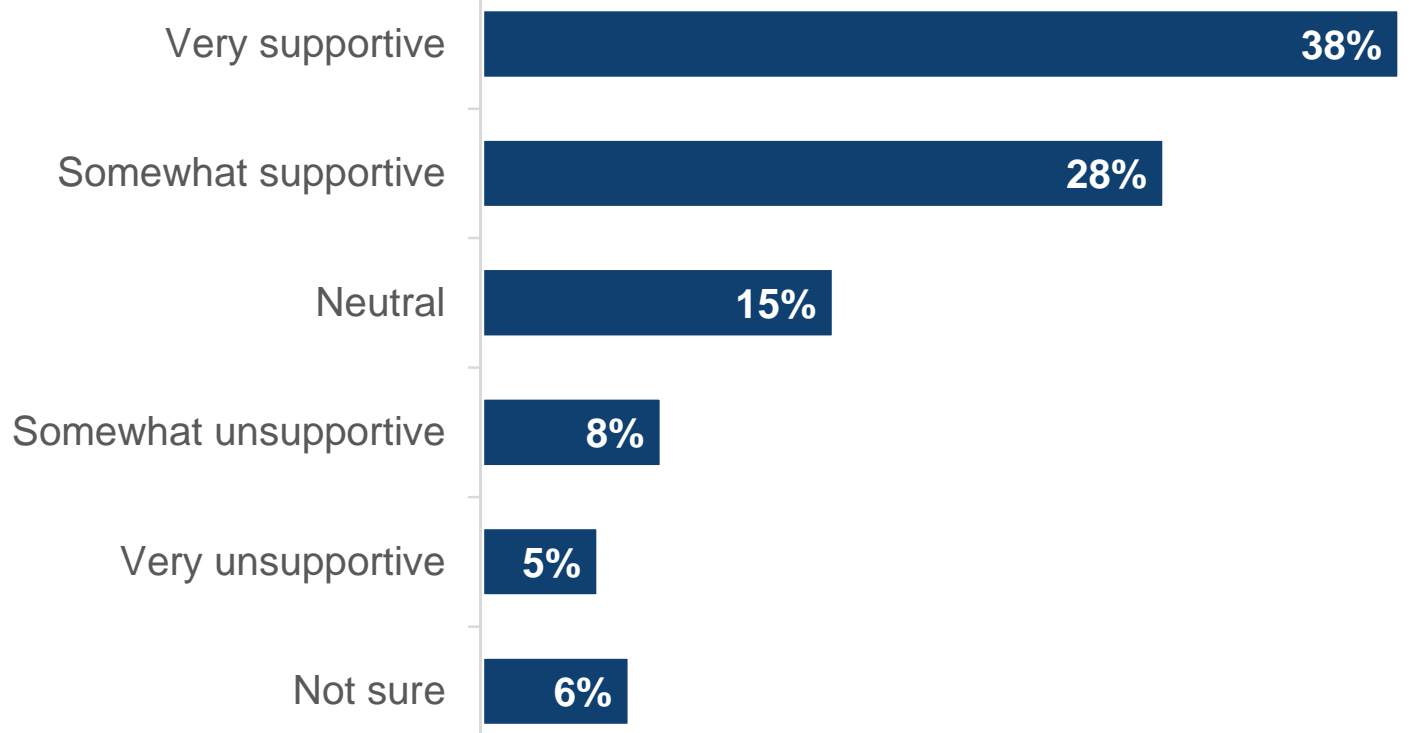

How supportive of its local LGBTQ community is the city or town in which you live? $(n=530)$ 


\section{BEING AN "OUT” LGBTQ PERSON}

Most LGBTQ participants in this study are fully or mostly out to family, friends, and coworkers. For these participants age $45+$, only $10 \%$ came out before age 17 , but $43 \%$ were out by age 24 , and $69 \%$ by age 34 .

\section{Level of Being "Out"}

Fully out to all family, friends and coworkers

Mostly out to family, friends and coworkers

$18 \%$

Out to some people in my life, but not everyone

I am out to only a small number of people or not out

\section{$5 \%$}

How "out" are you as an LGBTQ community member? Please choose the best response. $(n=530)$

At what age did you "come out" as an LGBTQ person? We know coming out is a process. Please provide the best answer. $(\mathrm{n}=530)$ 


\section{LGBTQ IDEAL LIVING ENVIRONMENTS}

A majority (55\%) of U.S. LGBTQ adults age 45+ want to stay in their own home during their retirement years. A good number also want to explore LGBTQ-specific living environments.

$$
\text { Ideal Living Environments During Retirement }
$$

Stay in my current home or apartment

Own a home during my retirement years

Live in a LGBTQ-friendly assisted living community

Live in a place with lower cost of living

Resort community known to be LGBTQ-friendly

Downsize to a smaller home or apartment

With friends/roommates to share costs and tasks

Rent a home during my retirement years

Live with my children, siblings, or other relatives

None of the above $1 \%$

Let's think about your retirement years. How would you describe your ideal environment for your retirement?

Please mark all that are both ideal and realistic for you. $(n=530)$ 


\section{METHODOLOGY}

AARP engaged Community Marketing \& Insights (CMI) to conduct a national quantitative research study among the LGBTQ community age 45 and older. Topics included healthcare, the economy, financial issues, independent living, long-term care, caregiving, and retirement issues.

Online survey invitations were sent to a random sample of Community Marketing \& Insights' LGBTQ research panel age 45 or over. A total of 530 people completed the survey.

CMI's research panel was developed over a 25-year period through partnerships with over 300 LGBTQ media, events, organizations, and social media. The panel is only used for research purposes; never marketing. Importantly, the panel mostly includes "out" LGBTQ community members who interact with LGBTQ media and organizations. The research most likely underrepresents older LGBTQ Americans who are more "closeted" about their sexual orientation or gender identity.
Because the survey was longer than typically fielded for $\mathrm{CMI}$ research (about 15 minutes), participants were offered a gift card incentive to complete the survey.

The survey was launched on December 5, 2020, and closed on December 16, 2020.

Percentages of some questions may exceed $100 \%$ due to rounding or the use of multiple response question formats.

Due to an oversample of transgender participants, results were weighted $46 \%$ gay and bisexual men, $46 \%$ lesbian and bisexual women, and $8 \%$ transgender and non-binary community members.

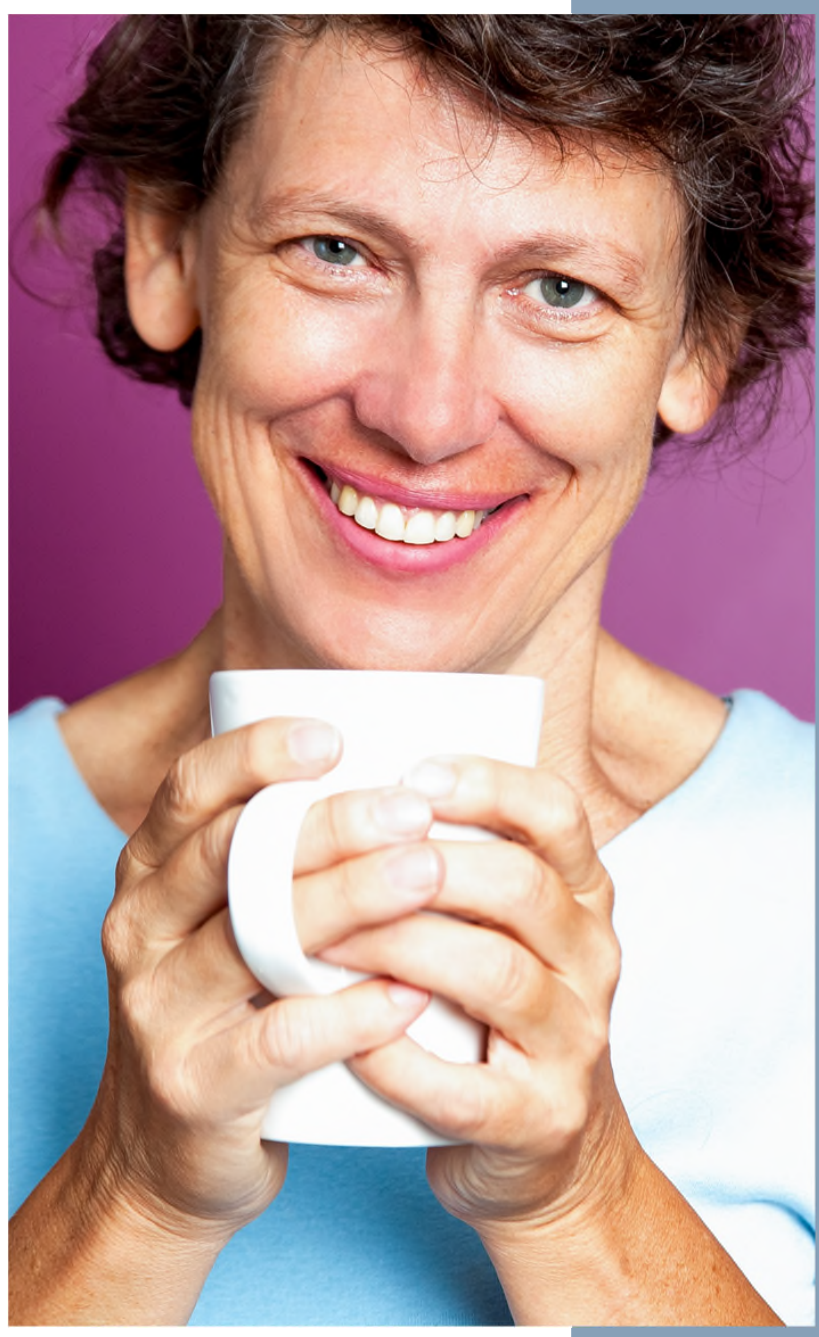




\section{ABOUT AARP}

AARP is the nation's largest nonprofit, nonpartisan organization dedicated to empowering Americans 50 and older to choose how they live as they age. With nearly 38 million members and offices in every state, the District of Columbia, Puerto Rico, and the U.S. Virgin Islands, AARP works to strengthen communities and advocate for what matters most to families with a focus on health security, financial stability and personal fulfillment. AARP also works for individuals in the marketplace by sparking new solutions and allowing carefully chosen, high-quality products and services to carry the AARP name. As a trusted source for news and information, AARP produces the nation's largest circulation publications, AARP The Magazine and AARP Bulletin. To learn more, visit www.aarp.org or follow @AARP and @AARPadvocates on social media.

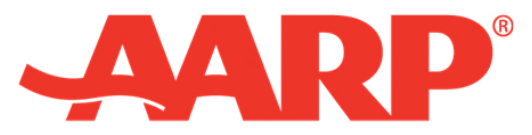

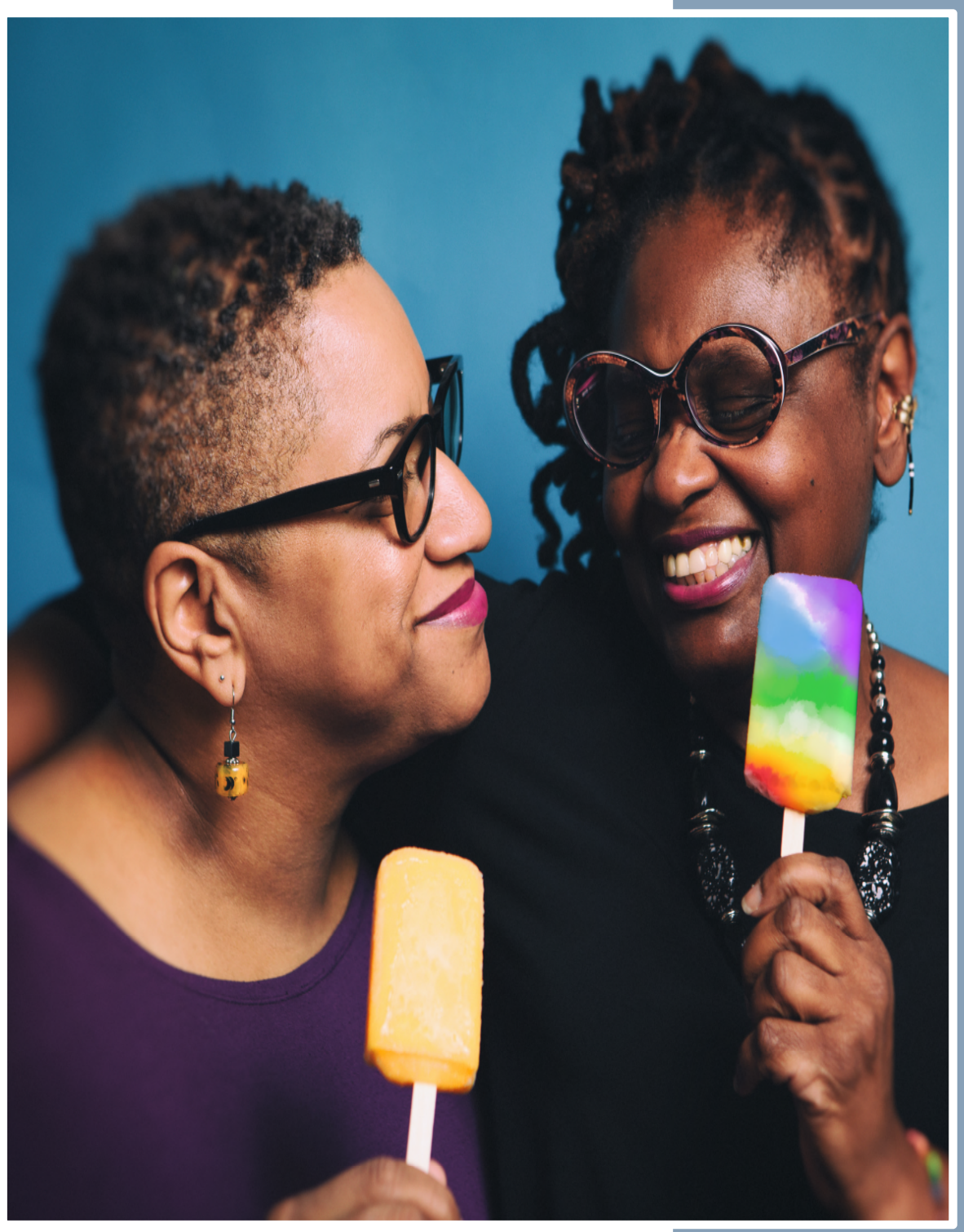




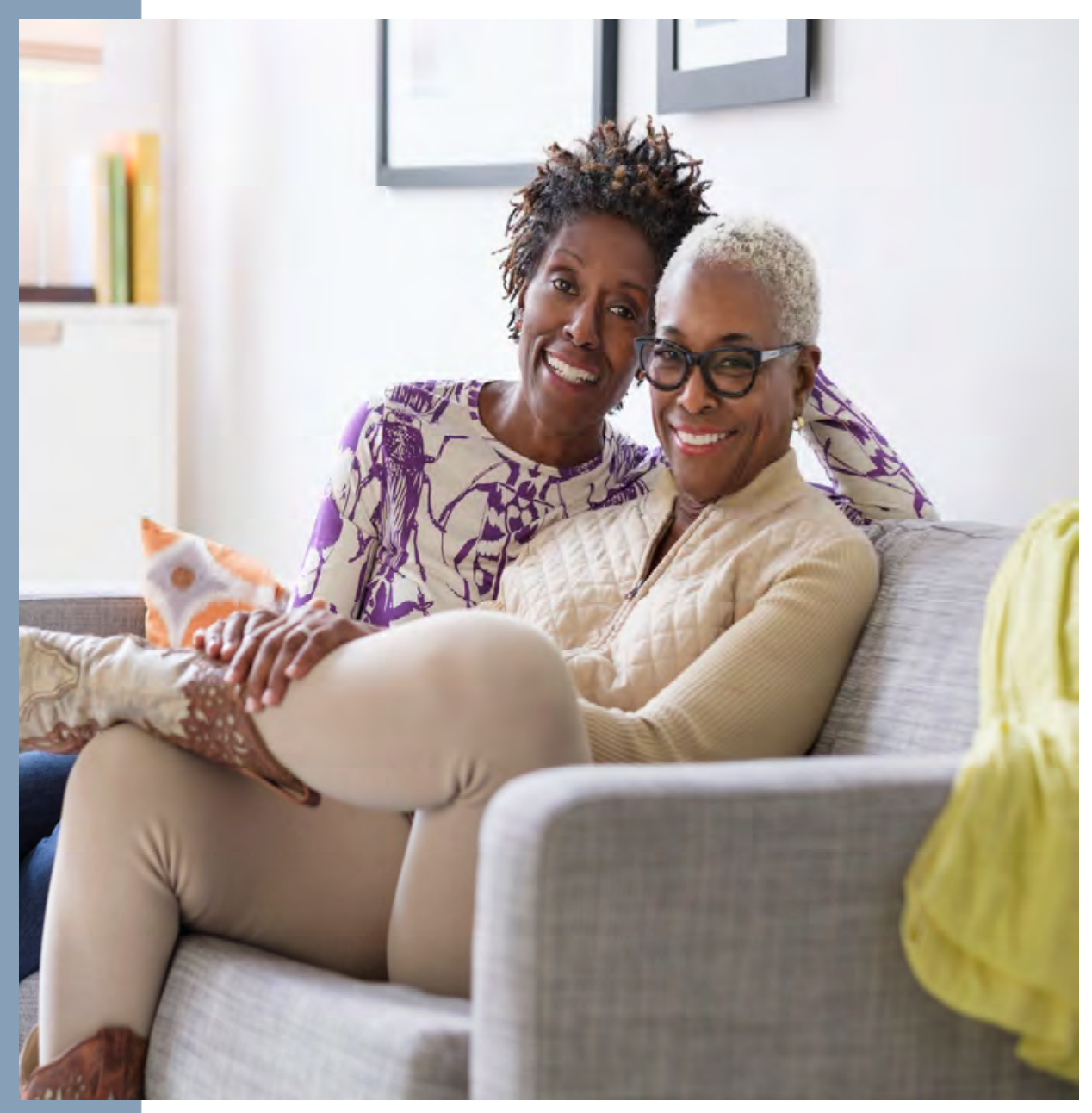

AARP

CONTACT

Cassandra Cantave,

CCantave@aarp.org

For media inquiries, please contact media@aarp.org.

This research was designed and executed by AARP Research. 